\title{
Fatigue Deformation Mechanisms of Zirconia Ceramics
}

\author{
Shih-Yu Liu* and I-Wei Chen* \\ Department of Materials Science and Engineering, University of Michigan, \\ Ann Arbor, Michigan 48109-2136
}

\begin{abstract}
Two distinct fatigue deformation mechanisms, microcracking and transformation plasticity, have been identified in 3Y-TZP and Mg-PSZ. Microcracking is dominant in 3Y-TZP, while transformation plasticity is more evident in Mg-PSZ. However, the proportion of these two mechanisms is dependent on the frequency and stress amplitude, with transformation plasticity favored at low frequency and high stress. Generally, microcracks form in the tensile half-cycle and partly close in the compressive half-cycle, whereas transformation from the tetragonal to the monoclinic phase, as well as the reverse transformation, can occur in both tension and compression. Under stress-controlled cycling, although the initial hysteresis loop is highly asymmetric with respect to the stress, cyclic softening and the development of an internal stress cause it to gradually evolve to yield an essentially symmetric cyclic stress-strain curve. [Key words: zirconia, fatigue, deformation, hysteresis, phase transformation.]
\end{abstract}

\section{Introduction}

$\mathbf{I}$ $\mathrm{T}$ IS well-known that cyclic loading of metallic materials into the plastic range changes their stress-strain response. Most engineering metals exhibit cyclic hardening or softening behavior, depending upon their original metallurgical treatment, such as degree of cold work and annealing. Direct evidence of cyclic hardening or softening can be obtained by observing the shape change of the hysteresis loop, which is the cyclic stressstrain response under either stress-controlled or straincontrolled conditions. If the hysteresis loop gradually tilts toward the stress (strain) axis during cycling, the material undergoes cyclic hardening (softening). Generally, after cycling the material for a number of cycles, a short time compared to the fatigue life, the hysteresis loops will stabilize and achieve the steady-state response. This steady-state response is characterized by the so-called cyclic stress-strain curve, which is the locus of the tips of the stable hysteresis loops obtained under fully reversed loading conditions at various stress or strain amplitudes. A comparison of the cyclic and monotonic stressstrain curves allows one to assess the cyclically induced changes in deformation resistance: if the cyclic stress-strain curve lies above (below) the monotonic stress-strain curve, the material cyclically hardens (softens). ${ }^{1}$

The cyclic fatigue behavior of ceramic materials has received increasing attention in recent years. ${ }^{2-37}$ However, the majority of these studies now focus on the fatigue life and crack propagation, with very little attention directed to the cyclically induced changes in deformation resistance. In the present paper we have conducted a systematic investigation of the cyclic stress-strain response of two zirconia ceramics and compared that with the monotonic stress-strain response. By analyzing

K.T. Faber-contributing editor

Manuscript No. 196635. Received June 17, 1991; approved January 2, 1992. Supported by the National Science Foundation under Grant No. DMR 8807024 .

${ }^{\star}$ Member, American Ceramic Society. the characteristics of the hysteresis loops, we are able to identify the dominant deformation mechanisms in fatigue.

The brittleness of ceramic materials and the capacity for transformation plasticity in zirconia dictate that the hysteresis loops of these materials take on special features not commonly found in the fatigue literature. In the next section, these special features are first outlined in a schematic form to familiarize the reader with the central considerations when viewing a hysteresis loop in a zirconia ceramic. The experimental aspects are described in Section III and the experimental results are presented and interpreted in Section IV. They are followed by further discussion on the fatigueinduced evolutions of deformation resistance and damage in Section V and conclusions in Section VI.

\section{Synopsis}

The steady-state hysteresis loop for a typical dense, homogeneous material, after an initial strain hardening or softening transient is introduced, is schematically shown in Fig. 1(a). It consists of two linear portions $(A B$ and $C D)$, which occur after the elastic unloading and loading from the peak loads, and two nonlinear portions $(B C$ and $D A)$. Usually, the hysteresis loop is approximately symmetric with respect to the origin, with a negative (positive) curvature associated with the loading (unloading) portion, $D A(B C)$. The hysteresis loop retains its stable shape until the emergence of incipient fatigue cracks. If such cracks open in tension but close on compression, they will cause a drastic decrease in the peak load or a largc increment of the peak strain. This is depicted in Fig. 1(b) (from point $\mathrm{A}$ to $\mathrm{E}$ ) for the constant strain condition and Fig. 1(c) (from $A$ to $E^{\prime}$ ) for the constant stress condition. In both cases, part of the tensile unloading portion acquires a negative curvature ( $F C$ in Fig. $1(b)$ and $F^{\prime} C$ in Fig. 1(c)) ${ }^{38}$

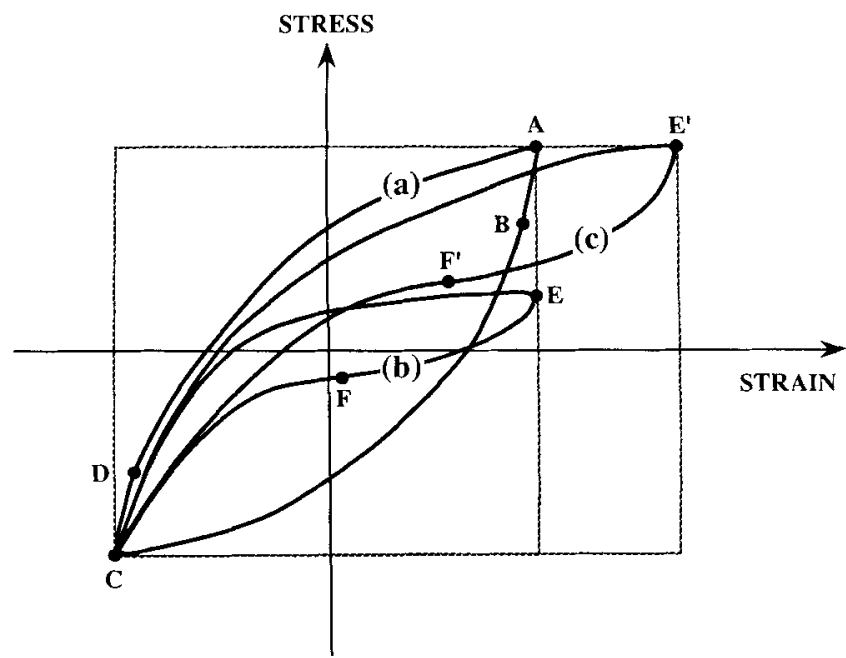

Fig. 1. Stress-strain response of (a) a dense, elastic-homogeneous plastic material, (b) a cracked material under constant strain-controlled condition, and (c) a cracked material under constant stress-controlled condition. 
This latter aspect is of particular significance for ceramics which have little plasticity but are prone to microcracking.

The above discussion on the hysteresis loop can be stated more generally. There are two common causes which can result in nonlinearity in a steady-state hysteresis loop: material plasticity and configurational changes. ${ }^{39}$ Material plasticity may arise from various kinds of deformation mechanisms, such as dislocation motion for metals, viscoelastic flow for polymers, and phase transformation for zirconia ceramics. Twinning or interface-motion are also common causes of material plasticity. On the other hand, configurational changes involve only the opening and closing of cracks, either macrocracks or microcracks. With few exceptions, we believe most cyclic plastic deformation mechanisms at the steady state exhibit a negative curvature during loading and a positive curvature during unloading, i.e., they are symmetric with respect to the zero stress/strain state after extended cycling. In contrast, configurational changes involving crack opening and closing always result in a negative curvature in both loading and unloading. The negative curvature during unloading ( $F C$ in Fig. 1(b) and $F^{\prime} C$ in Fig. 1(c)) is due to recovery of stiffness following crack closure.

Studies on zirconia-containing ceramics have identified phase transformation (from tetragonal $(t)$ to monoclinic $(m)$ phase) and microcracking as the main deformation mechanisms in monotonic loading. ${ }^{4(1-43}$ Indeed, they are the main source of the enhanced fracture toughness. ${ }^{44,45}$ Several aspects of these mechanisms are important. First, the deformation resistance of transformation plasticity is higher in compression than in tension because of the dilatant nature of the tetragonal to monoclinic transformation operational in these materials. ${ }^{41.42}$ Second, there is an alignment of microcracks normal to the axis of the maximal principal stress, and a corresponding reduction of the elastic stiffness in the same direction. ${ }^{43}$ Third, the magnitude of homogeneous plastic strain due to transformation and microcracking is no greater than the elastic strain in tensile loading at fracture even though the transformation strain on a local scale or in compression can be much higher. In the following, we will outline the basic features of the hysteresis loops based on the above considerations for zirconia ceramics. To make the plastic strain more evident, our hysteresis loops are plotted in stress and plastic strain only. In such a plot, the portions of elastic loading and unloading, $A B$ and $C D$, in Fig. 1(a), become vertical lines, unless the stiffness has degraded. This will become apparent in the following constructions.

A schematic of a transformation-induced hysteresis loop is shown in Fig. 2. The process of the development of a stable hysteresis loop can be appreciated by inspection of the first two loading cycles under a stress-controlled condition. Here, for simplicity, we assume that transformation initiates upon loading and its amount increases as the stress rises (point $\mathrm{A}$ to B). We further assume that the product phase has the same elastic stiffness as the parent phase, and that reverse transformation can occur if a certain frictional back stress is first overcome. The latter is represented by a vertical elastic portion $B C$ which is followed by reverse plastic deformation from point $\mathrm{C}$ to point $\mathrm{E}$. (It is also possible that, after the forward $t$ to $m$ transformation is reversed, some additional $t$ to $m$ transformation occurs in compression. Evidence for this will be experimentally examined later.) After a load reversal, the process repeats itself to complete the first loading cycle $(A B C D E F G)$. Because of the stress-asymmetric characteristic of phase transformation, the peak strain in compression (point $\mathrm{E}$ ) is less than that in tension (point B). Thus, instead of forming a closed loop, a finite residual plastic strain $(A G)$ is formed. If additional phase transformation can be triggered during the subsequent loading cycle $(G H I J K L M)$, a larger peak strain (point $\mathrm{H}$ compared to point $\mathrm{B}$ ) will be reached. However, less residual strain will be accumulated in the second cycle ( $G M$ compared to $A G$ ) because of the gradual ex-

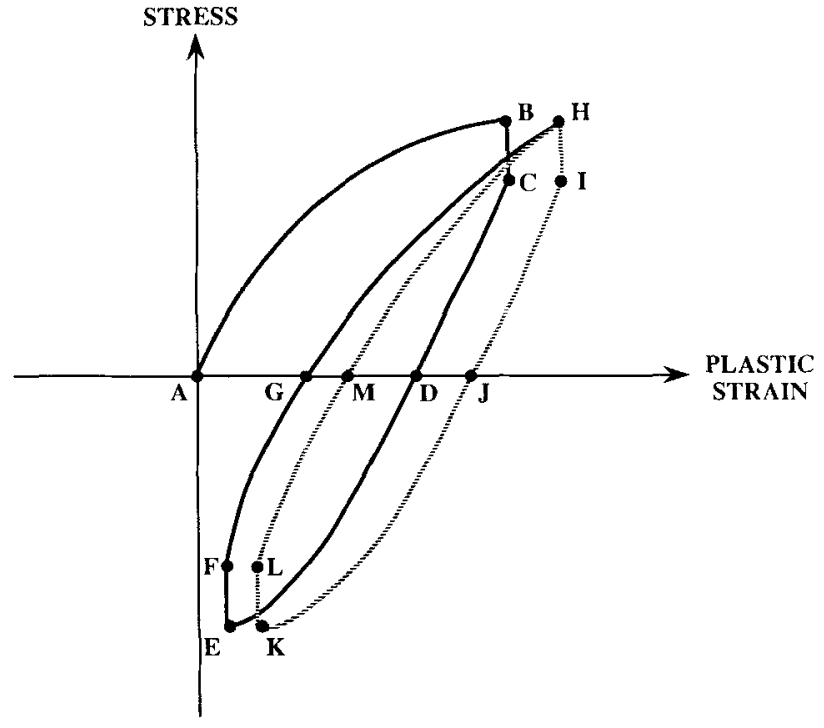

Fig. 2. Evolution of the transformation-induced hysteresis loops during stress cycling.

haustion of phase transformation. In reality, the number of fatigue cycles to reach this exhaustion depends upon stress state, stress rate, and prior history. ${ }^{35}$ For simplicity, we may assume this exhaustion process to complete within the first two cycles so that a stable, closed hysteresis loop (MHIJKLM, represented by the dashed line in Fig. 2) forms in the third loading cycle. (In reality, a significant number of cycles may be required to complete this exhaustion process when the hysteresis loop "creeps" in the direction of increasing tensile strain. This tendency is especially prominent given the stress asymmetry of transformation plasticity as discussed in Section IV(4) and Ref. 35.) The mechanism involved at the steady state is the forward $(t$ to $m$ ) and reverse ( $m$ to $t$ ) phase transformation; both may occur in tension and in compression.

A schematic of the development of the hysteresis loop caused by microcracking is shown in Fig. 3. We first consider crack accumulation (in tension) and closure (in compression) which result in a change in elastic stiffness. Referring to Fig. 3(a), the initial vertical portion $(A B)$ represents elastic loading of the uncracked specimen. (With preexisting cracks, $A B$ will have a positive slope even in the initial loading in our representation.) If we assume that microcracking occurs at a threshold stress (point $\mathrm{B}$ ), then the subsequent curving $(B C)$ may be used to indicate plastic deformation from progressive microcrack formation, crack opening, and the release of residual strain. This process continues to the peak stress. During elastic unloading, since the cracked specimen has a lower elastic stiffness than the uncracked one, the linear portion $(C D)$ acquires a positive slope initially. Below a certain stress level, contacts between microcrack surfaces begin to form and bear load. This may occur even though the overall macroscopic stress is still tensile (point D). From this point on, a gradual recovery of the stiffness continues until all the cracked surfaces are closed $(D E)$, which usually requires a certain compressive stress (point E). Subsequent compression is borne by a fully recovered and dense specimen. Thus, a vertical line $(E F)$ resumes representing elastic compression of a seemingly uncracked specimen. Unloading from the peak compressive stress (point F) causes the stress-plastic strain curve to retrace a similar vertical line $(F G)$ until microcracks reopen. The crack reopening stress (point $G$ ) is always higher than the crack closure stress (point E) because of the ubiquitous frictional force which exists between two crack surfaces. The hysteresis loop continues and ends at point $\mathrm{H}$ for the first cycle $(A B C D E F G H)$. During the second cycle, if additional microcracking damage occurs in tensile loading, a larger maximum plastic strain will be formed at point $I$. If so, the unloading 


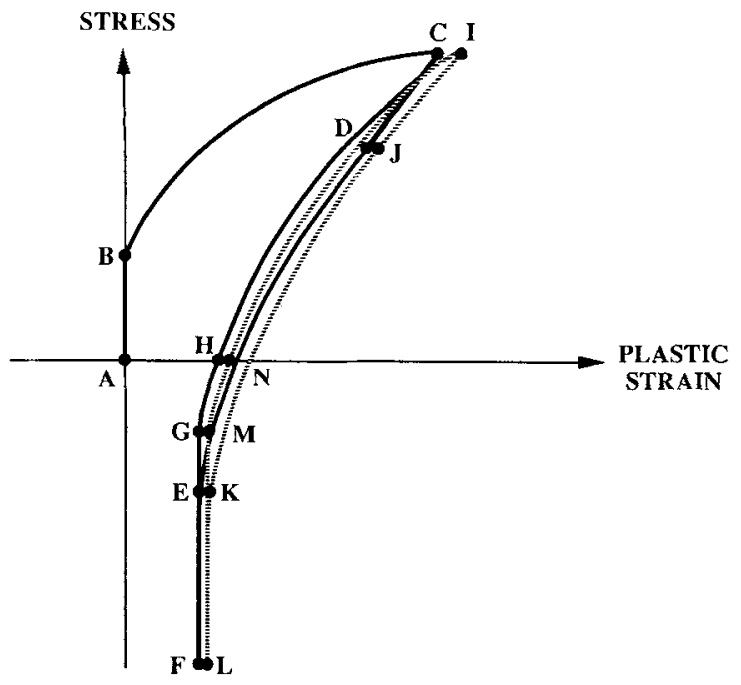

(a)

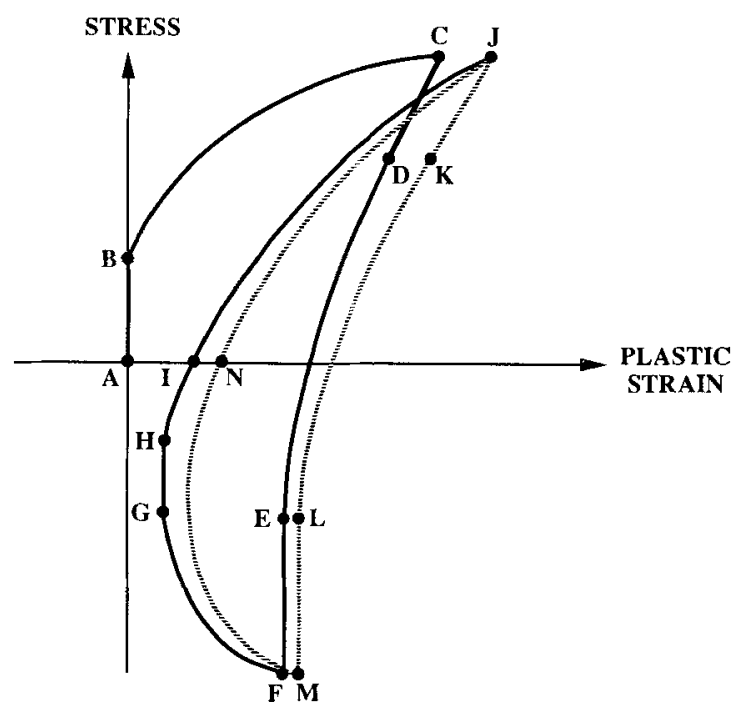

(b)

Fig. 3. Evolution of the microcracking-induced hysteresis loops during stress cycling (a) without crack surface friction and sliding, and (b) with crack surface friction and sliding.

stiffness (the slope of $I J$ in Fig. 3(a)) will be less than that of the first cycle ( $C D$ in Fig. 3(a)) because of a higher density of microcracks. The second cycle continues through $H I J K L M N$ and has a smaller accumulation $(H N)$ than that of the first cycle $(A H)$ because of exhaustion. As before, if microcracking reaches its saturation state within the first two cycles, a stable closed hysteresis loop (NIJKLMN, as represented by the dashed line in Fig. 3(a)) forms in the third cycle and retains its shape during subsequent cycling. This hysteresis loop results entirely from the opening and closing of a constant number of microcracks, with friction against crack opening.

There is a possible variation of the above case involving microcracking which is schematically represented in Fig. 3(b). Here we allow an additional sliding mechanism to operate on the microcrack surfaces and on the ligaments (such as grain boundaries or shear bands) between them. Such slidingrelated deformation may be regarded as anelastic in nature. Hence, for example, even after the peak compressive load is reached, additional compressive strain can still accumulate during unloading and can result in the curve $F G$ of a negative slope, shown in Fig. 3(b). When the anelastic strain is finally exhausted, a vertical unloading portion $(G H)$ then appears and the hysteresis loop continues. The steady-state hysteresis loop $(N J K L M N)$ is again represented by dashed lines in Fig. 3(b) and is attributed to the opening and closing of a constant number of microcracks with some additional frictional sliding.

It is important to note that both Figs. 3(a) and (b) have the characteristic negative curvature associated with the tensile unloading portion which is distinctly absent in Fig. 2. When both phase transformation and microcracking are operational, the hysteresis loop can be constructed by superimposing the two loops of Figs. 2 and 3. The curvature of the tensile unloading curve may vary from negative to positive when the dominant mechanism changes from microcracking to phase transformation. When the contribution of both material plasticity (specifically, reverse phase transformation) and configurational change (specifically, microcrack closure) are of comparable magnitude, a straight unloading line may result. Such a hysteresis loop is shown schematically in Fig. 4, which is quite different in shape from the loops shown in Figs. 2 and 3. Nevertheless, some similarities may still be noted. For example, the unloading stiffness (the slope of $G H$ ) and the accumulated plastic strain $(F J)$ in the second cycle are both smaller than those of the previous cycle (the slope of $C D$, and $A F$, respectively).

In the present study of zirconia-based ceramics (Mg-PSZ and 3 Y-TZP), we observed hysteresis loops of all the above variety (Figs. 2 to 4 ) depending on the material and testing condition. The insight obtained by comparison of the experimentally observed loops and the above schematics allowed us to identify the dominant deformation mechanisms in each case.

\section{Experimental Procedure}

\section{(1) Materials}

The materials studied are two commercially available zirconias. These are 8 to 9 mol\% magnesia partially-stabilized zirconia (Mg-PSZ) and 3 mol\% yttria-stabilized zirconia (3Y-TZP). Microstructures of these two materials are very different. Mg-PSZ contains a coarse grain (about $50 \mu \mathrm{m}$ ) cubic matrix interspersed with lens-shaped tetragonal precipitates. When this material is stressed, phase transformation of the tetragonal phase to a monoclinic phase occurs near the crack tip, which greatly enhances its fracture resistance. Large transformation plasticity can also be observed in compression ${ }^{40,41}$ and, to a much lesser extent, in tension, as will be shown in the next section. 3 Y-TZP, on the other hand, contains primarily a fine-grained (about $0.38 \mu \mathrm{m}$ ) tetragonal phase which also undergoes mechanically induced martensitic transformation at the crack tip. However, the extent of the transformation is rather limited on the fracture surfaces and even more so in

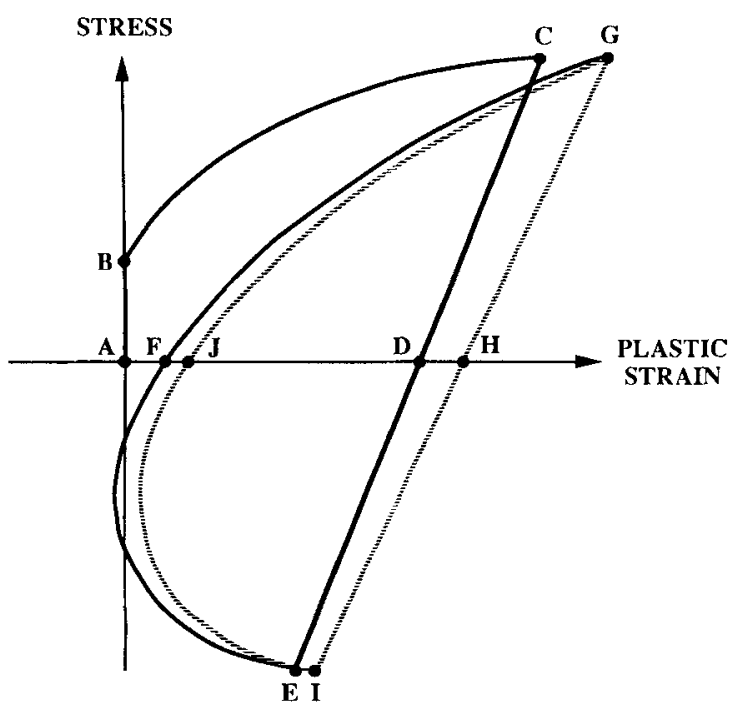

Fig. 4. Evolution of the hysteresis loops caused by both phase transformation and microcracking. 
both compression and tension tests. ${ }^{46}$ Some mechanical properties of those materials are listed in Table I, with further information available elsewhere..$^{35}$

\section{(2) Mechanical Testing}

Specimens used in this study have a $16-\mathrm{mm}$ gauge length and a 6-mm gauge diameter, which were designed according to ASTM E606. ${ }^{47}$ A 220 -grit diamond wheel was used to grind the as-received cylindrical bars to specification. In this operation, a large amount of material was removed around the gauge section so that any surface inhomogeneity introduced during sintering would not remain. A final mirror surface finish was obtained by polishing with a $1-\mu \mathrm{m}$ diamond paste.

Load-controlled, uniaxial, fully reversed, push-pull fatigue experiments were performed using a computer-controlled servohydraulic testing machine (MTS 810, MTS Systems Corp., Minneapolis, $\mathrm{MN}$ ). An axial extensometer having a gauge length of $8 \mathrm{~mm}$ was attached to the central portion of the specimen by two springs. Since the specimen surface was rather hard and smooth, a drop of epoxy (Super Bonder 495, Loctite Corporation, Newington, CT) was applied between the knife edge of the extensometer and the specimen to prevent slippage. Since zirconia has a relatively large coefficient of thermal expansion and strains were measured in the present study are small, special precautions were taken to minimize the temperature fluctuation of the specimen and the extensometer during the test. A foil-type thermocouple was attached to the specimen to monitor the temperature. Stroke, load, axial strain, and radial strain were simultaneously recorded for each cycle. Excellent alignment (less than $3 \%$ bending component at a stress level of $300 \mathrm{MPa}$ ) of the loading train was achieved and verified by axial strain measurement of three strain gauges at $120^{\circ}$ intervals around the circumference of the specimen.

\section{Results and Analysis}

\section{(1) Monotonic Stress-Plastic Strain Curve}

The tensile stress-strain curves of Mg-PSZ and 3Y-TZP are shown in Fig. 5. At fracture, approximately $40 \%$ of the total strain in Mg-PSZ is plastic, while essentially all the strain is elastic in 3 Y-TZP. On this basis, 3 Y-TZP may be regarded as a prototype, single-phase, brittle ceramic of a relatively homogeneous microstructure, whereas Mg-PSZ is more plastic and representative of a transformable brittle ceramic.

The stress-strain response of Mg-PSZ and 3Y-TZP is different in tension and in compression. To demonstrate this, the stress-plastic strain curves in tension and compression are plotted together and shown in Fig. 6 . The plastic strain is obtained by subtracting the elastic portion (calculated from $\left.\sigma / E_{\text {apparem }}\right)$ from the total strain. Here $\sigma$ is applied stress and $E_{\text {apparen }}$ is the highest apparent Young's modulus determined from the slope of the steepest portion of the stress-strain curve. For Mg-PSZ, the $E_{\text {apparent }}$ was obtained from the slope of the stress-strain curve between 0 and $\pm 50 \mathrm{MPa}$. Very pronounced plastic deformation is apparent in tension but not in compression, indicating a strong tendency for stress asymmetry. This is consistent with the dilatant characteristic of the tetragonal to monoclinic phase transformation. ${ }^{40,41}$ For 3Y-TZP, the steepest portion of the stress-strain curve is observed at the highest compressive load, in this case from -550 to $-600 \mathrm{MPa}$. Using the $E_{\text {apparent }}$ thus determined, the stress-

Table I. Properties of 3Y-TZP and Mg-PSZ at Room Temperature

\begin{tabular}{lcccc}
\hline & $\begin{array}{c}\text { Elastic } \\
\text { modulus } \\
(\mathrm{GPa})\end{array}$ & $\begin{array}{c}\text { Fracture } \\
\text { toughness } \\
\left(\mathrm{MPa} \cdot \mathrm{m}^{1 / 2}\right)\end{array}$ & $\begin{array}{c}\text { 4-point bend } \\
\text { strength* }^{*} \\
(\mathrm{MPa})\end{array}$ & $\begin{array}{c}\text { Tensile } \\
\text { strength } \\
(\mathrm{MPa})\end{array}$ \\
\hline 3Y-TZP & 210 & 5 & $850 \pm 65^{+}$ & 650 \\
Mg-PSZ & 195 & 8 & $675 \pm 20^{\ddagger}$ & 375 \\
\hline *Nominal & & 8 &
\end{tabular}

$9 \pi \times 16 \mathrm{~mm}^{3} *$ Standard deviation.

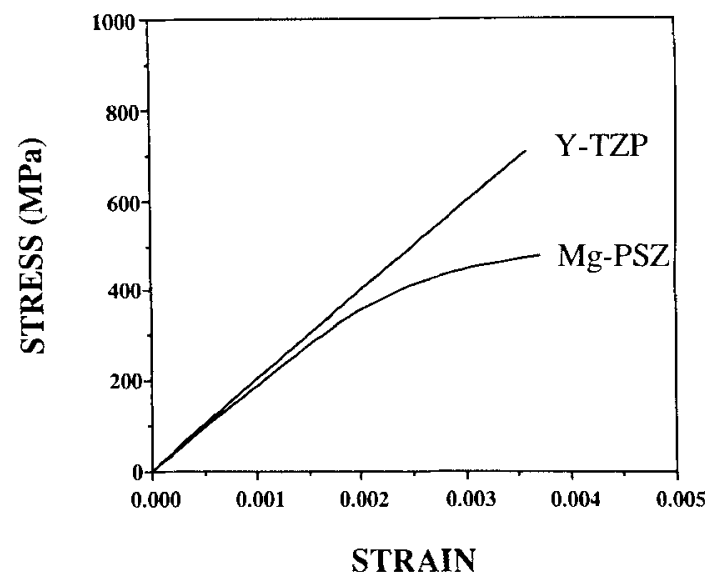

Fig. 5. Stress-strain curve of $\mathrm{Mg}$-PSZ (stress rate $=7 \mathrm{MPa} / \mathrm{s}$ ) and Y-TZP (stress rate $=5 \mathrm{MPa} / \mathrm{s}$ ) in uniaxial tension test.

plastic strain curve was obtained and plotted in Fig. 6. It exhibits a similar but much smaller plastic deformation in tension. Moreover, even in compression, the stress-plastic strain curve has a negative curvature in contrast to the positive one for Mg-PSZ in compression. This behavior suggests that there is little transformation plasticity and that the material contains preexisting microcracks which become closed under a large compressive load. Higher compressive stresses were not applied in these experiments to avoid buckling of the specimens. However, in previous work in our laboratory, the compressive yield stress of $\mathrm{Mg}$-PSZ was placed at around $-600 \mathrm{MPa}$ and that of 3 Y-TZP was beyond $-3.5 \mathrm{GPa}$. The present results are consistent with such information and clearly indicate that no significant yielding takes place in compression for either material in the stress range studied here.

\section{(2) Cyclic Stress-Plastic Strain Curve}

A series of hysteresis loops, at a constant frequency of $0.25 \mathrm{~Hz}$ but of different stress ranges, is shown in Fig. 7 for 3 YTTZP. For each stress level, the specimen was first fatigued for 100 cycles to saturate the accumulation of fatigue damage. Thus, these loops are essentially the steady-state oncs as evidenced by their closure. At the smallest stress range $( \pm 100 \mathrm{MPa})$ the curve resembles the closed loop MHIJKLM of Fig. 2, indicating that phase transformation is the main mechanism for plastic deformation. At the stress range of $\pm 200 \mathrm{MPa}$, the tensile unloading curve has a zero curvature similar to Fig. 4, indicating that microcracking and phase transformation are equally important. As the stress range becomes cven larger, the curvature of the tensile unloading

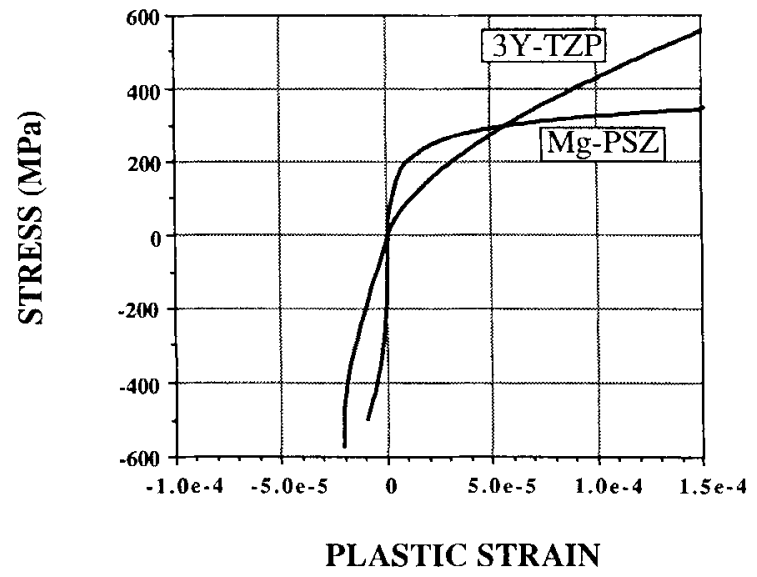

Fig. 6. Monotonic stress-plastic strain curve of Mg-PSZ (stress rate $=5 \mathrm{MPa} / \mathrm{s}$ ) and $3 \mathrm{Y}-\mathrm{TZP}$ (stress rate $=7 \mathrm{MPa} / \mathrm{s}$ ). 

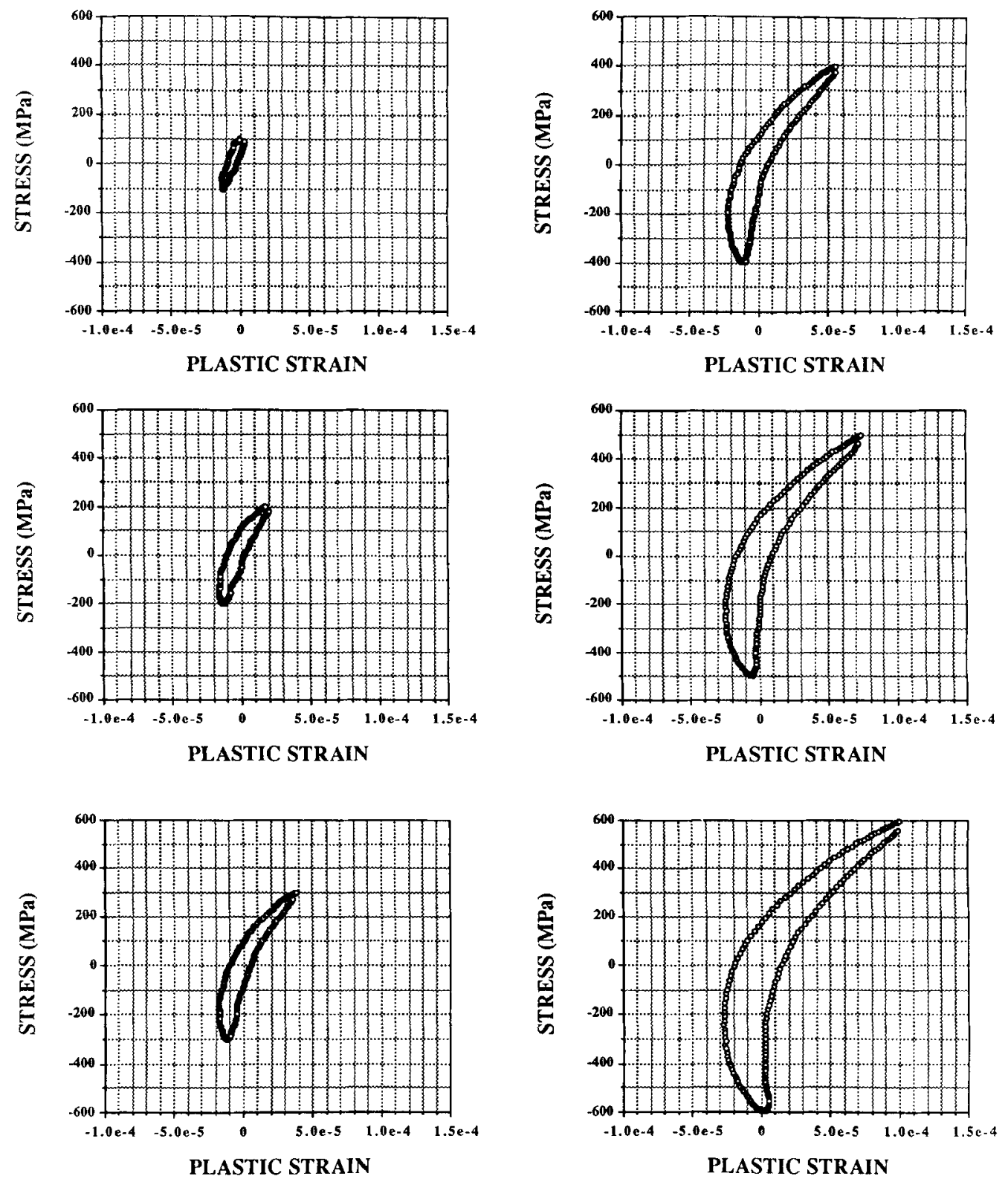

Fig. 7. Hysteresis loops of Y-TZP at $0.25 \mathrm{~Hz}$.

curve becomes more negative, which indicates that microcracking gradually dominates over phase transformation.

A cyclic stress-plastic strain curve is now constructed by connecting the tips of hysteresis loops at different stress amplitudes. This is shown in Fig. 8, which has an appearance similar to that of the monotonic stress-plastic strain curve. This further verifies that microcracking is the dominant deformation mechanism in this material. The slight difference in the compression range between these two arises from the difference in the adoption of elastic constants. The elastic constant used for the cyclic stress-plastic strain curve was determined from the steepest portion of the unloading curve of the largest hysteresis loop, which occurs near the lowest end of the unloading curve and appears vertical in Fig. 8. Using this measure, however, other loops do not have a vertical portion at their peak compressive load, presumably because some microcracks are still not fully closed. Hence, the plastic strain is nearly zero at the peak compressive stress in the cyclic stressplastic strain curve, while the plastic strains at somewhat smaller compressive stresses are negative.

In a similar manner, the stable hysteresis loops of Mg-PSZ were obtained. In one experiment, the specimen was first

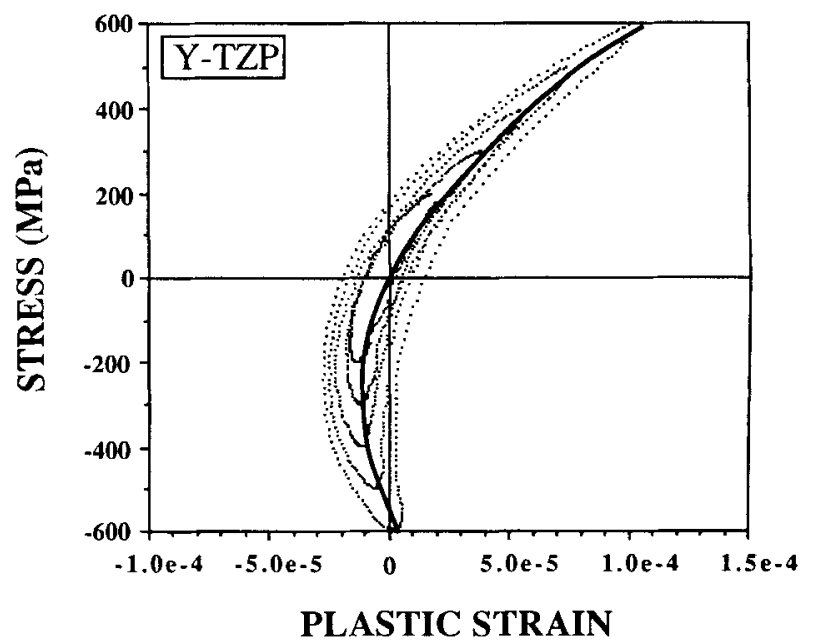

Fig. 8. Cyclic stress-plastic strain curve of Y-TZP at $0.25 \mathrm{~Hz}$ (Dash lines are hysteresis loops at different stress amplitudes.) 

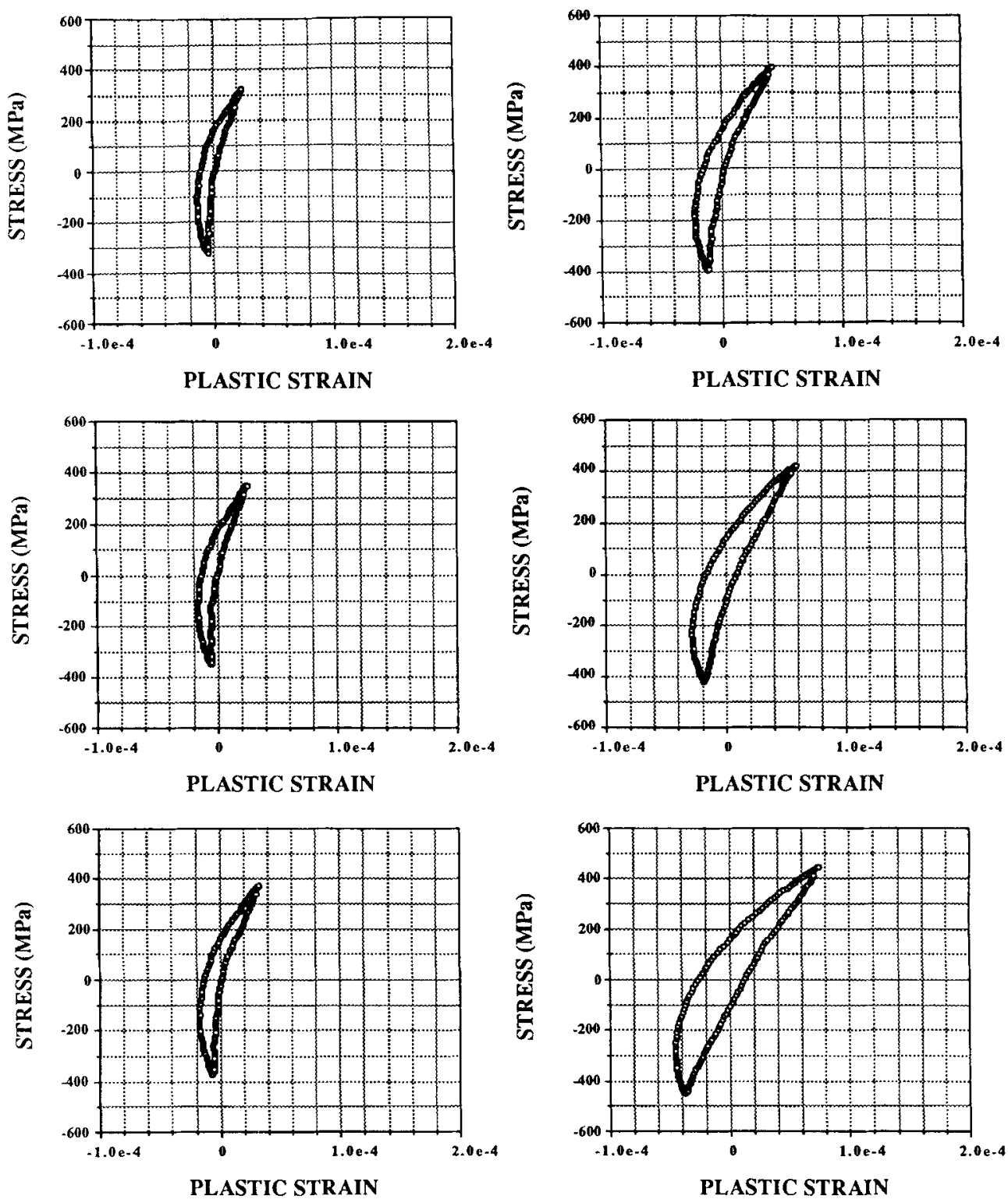

Fig. 9. Hysteresis loops of Mg-PSZ at $0.25 \mathrm{~Hz}$. The specimen has been prefatigued at $\pm 300 \mathrm{MPa}$ for 100000 cycles.

prefatigued at a frequency of $5 \mathrm{~Hz}$ and a stress range of $\pm 300 \mathrm{MPa}$ for $10^{5}$ cycles. The specimen was then fatigued at $0.25 \mathrm{~Hz}$ and at various stress amplitudes above $\pm 300 \mathrm{MPa}$, which quickly established the steady-state hysteresis loops. These are shown in Fig. 9. It is noted that as the stress range becomes larger, the tensile unloading curvature becomes less negative, which is just opposite to the case in 3Y-TZP. At the highest stress range, a nearly straight unloading portion is obtained, which indicates that both microcracking and phase transformation are of a comparable magnitude during cyclic deformation of Mg-PSZ. We have similarly constructed a cyclic stress-plastic strain curve from these plots, which is shown in Fig. 10. It is quite similar to the monotonic stress-plastic strain curve in tension but not so in compression. We shall return to this point in Section V.

From this we have found that the cyclic deformation behaviors of these ceramics are strongly dependent on the loading rate (stress rate or frequency). Thus, the cyclic stress-plastic strain curves shown in Figs. 8 and 10, while representative, are applicable only for the specific test conditions under which the data were obtained. This aspect is treated in more detail below.

\section{(3) Stress Rate Dependence and Transition of Mechanisms}

A set of hysteresis loops of 3Y-TZP at a constant stress range of $\pm 400 \mathrm{MPa}$, but different stress rates, is shown in

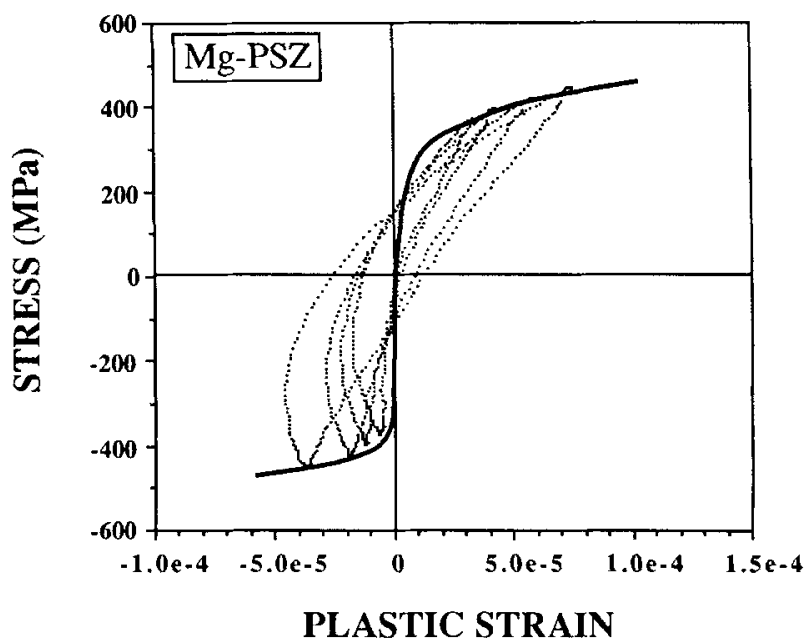

Fig. 10. Cyclic stress-plastic strain curve of $\mathrm{Mg}-\mathrm{PSZ}$ at $0.25 \mathrm{~Hz}$. The specimen has been prefatigued at $\pm 300 \mathrm{MPa}$ for 100000 cycles. (Dash lines are hysteresis loops at different stress ranges.) 


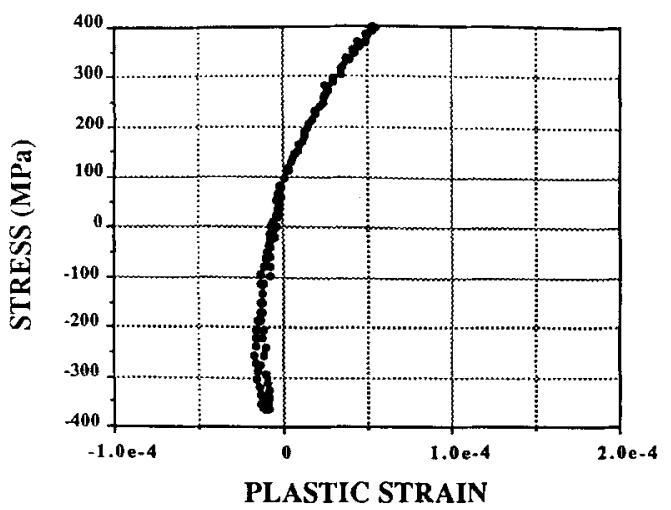

(a)

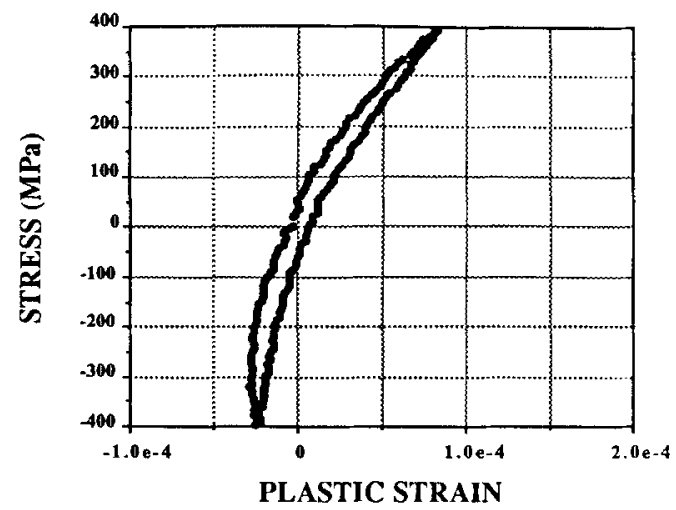

(c)

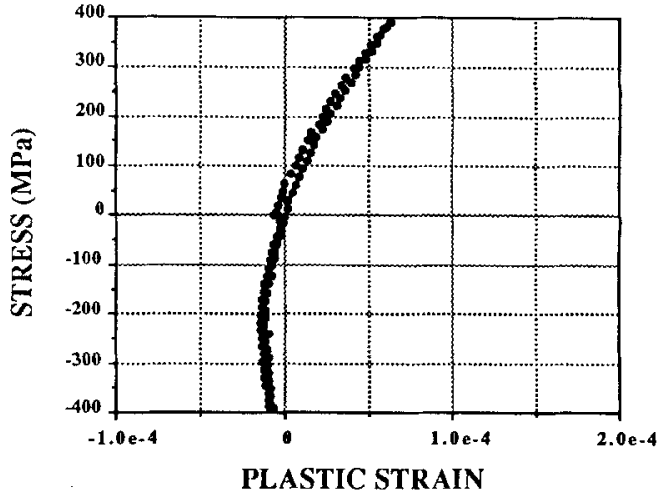

(b)

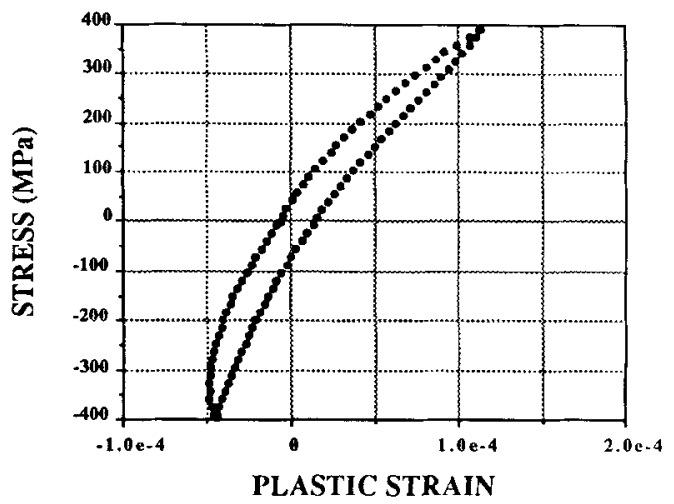

(d)

Fig. 11. Hysteresis loops of 3 Y-TZP at different stress rates: (a) $8 \mathrm{GPa} / \mathrm{s}$, (b) $800 \mathrm{MPa} / \mathrm{s}$, (c) $80 \mathrm{MPa} / \mathrm{s}$, (d) $8 \mathrm{MPa} / \mathrm{s}$.

Fig. 11. The above stress range was chosen to coincide with the mean fatigue limit at $50 \%$ failure probability, over a runout cycle of $10^{4}$ at a stress ratio of -1 and a stress rate of $1.6 \mathrm{GPa} / \mathrm{s} .{ }^{35}$ The common feature of these hysteresis loops is the negative curvature of the tensile unloading curve, as expected for microcracking. At the highest stress rate of $8 \mathrm{GPa} / \mathrm{s}$ (Fig. 11(a)), the loading and unloading curves overlap. This suggests that no additional microcracking is induced at this stress rate and stress range and that opening and closing of preexisting microcracks are fully reversible. As the stress rate decreases (Figs. 11(a) to (d)), the plastic strain at the maximum tensile stress increases, while that at the maximum compressive stress decreases. In addition, the curvatures of the unloading curves become less negative and the loop widens. This can be rationalized by an increasing contribution from transformation plasticity, which is known to have a very strong strain rate sensitivity. Indeed, if we assume that the hysteresis loop at the highest stress rate (Fig. $11(a)$ ) is due entirely to microcracking and that microcracking is rate-insensitive, we can then subtract that from the other loops at a lower stress rate to assess the contribution of transformation plasticity. The subtracted results are shown in Fig. 12. The resultant hystersis loops all have features consistent with those of transformation-related hysteresis loops depicted in Fig. 2. They expand as the stress rate decreases and are essentially responsible for the entire loop widths at various stress rates in Fig. 11. To assess the reversibility of this transformationinduced plastic strain, a series of fatigue tests at an increasing stress rate sequence was performed on the same specimen immediately following the previous decreasing stress rate tests. We found the hysteresis loop had been restored to its original shape when the stress rate was resumed. We thus conclude that the stress rate dependence of 3Y-TZP arises from the rate dependence of reversible phase transformation and not from microcracking. As additional evidence of the rate insensitivity of microcracking, we found that, after decreasing the stress rate from $8 \mathrm{GPa} / \mathrm{s}$ to $8 \mathrm{MPa} / \mathrm{s}$, as shown in Figs. 11 (a to d), the hysteresis loops at increasing stress rates from $8 \mathrm{MPa} / \mathrm{s}$ to $8 \mathrm{GPa} / \mathrm{s}$ were essentially indistinguishable from those obtained previously. This implies that additional cycling at the same stress but at a slower rate does not appreciably increase the microcrack density or its configuration.

In Mg-PSZ, the capacity for transformation plasticity is much larger. Some microcracking may also exist and may be further triggered by transformation plasticity. At a higher stress rate, transformation plasticity is mostly suppressed, as we found in the hysteresis loops shown in Fig. 13 at a rate of $200 \mathrm{MPa} / \mathrm{s}$. The common feature of these loops is a negative curvature of the tensile unloading curve and the overlap of the compressive loading and unloading curves, both of which were already found in Fig. 3(a) for the case of microcracking without crack-surface sliding. At a lower stress rate, as shown in Fig. 14, the hysteresis loops at higher stresses are rather similar in shape to those shown in Fig. 4, for the case of combined transformation plasticity and microcracking. Compared to Fig. 13, these loops have a much larger strain range due to the additional contribution from transformation plasticity. When two hysteresis loops of the same stress range are compared, the unloading curvature of the hysteresis loop at the lower stress rate (Fig. 14) is less negative than that at the higher stress rate (Fig. 13). This further verifies the operation of transformation plasticity. We also noticed that, at lower stress ranges, the hysteresis loops in Fig. 14 are almost closed, unlike those in Fig. 13. In addition, they have a negative slope subsequent to the compressive peak load, in contrast to the vertical loading/unloading portion in Fig. 13. Apparently, at the lower stress rates, anelastic deformation associated with crack-surface or shear band sliding, etc. is active enough to result in nearly closed loops in certain cases. Thus, the stress rate dependence of $\mathrm{Mg}$-PSZ arises both from the rate 


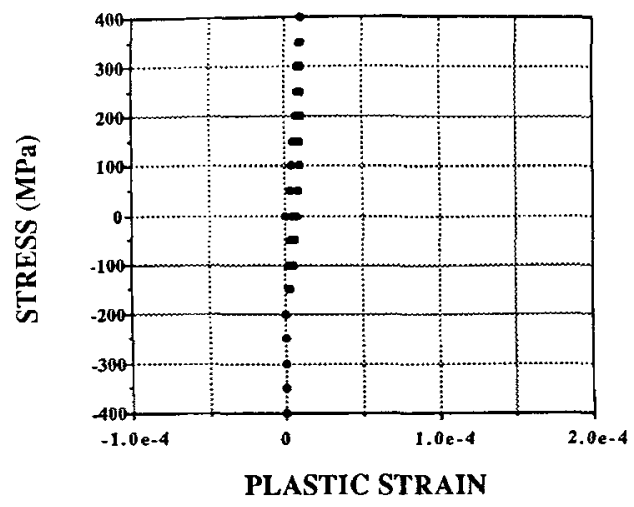

(a)

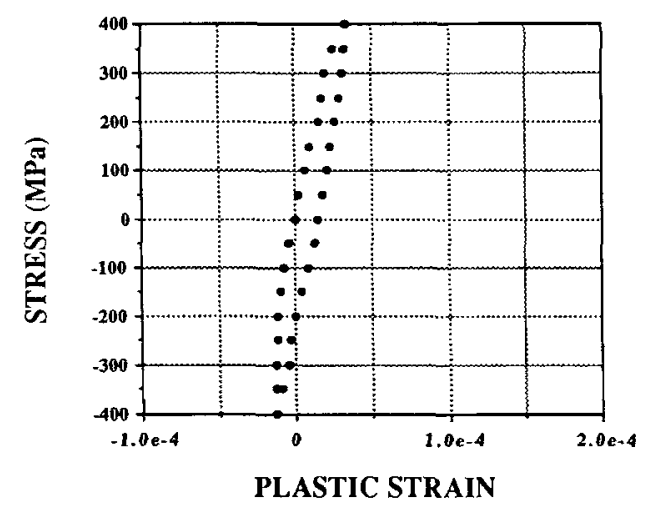

(b)

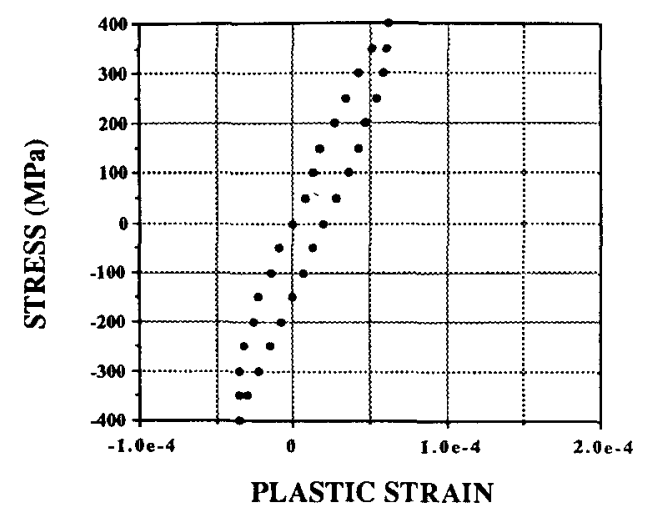

(c)

Fig. 12. Transformation strains in $3 \mathrm{Y}-\mathrm{TZP}$ at various stress rates. (a) $800 \mathrm{MPa} / \mathrm{s}$, (b) $80 \mathrm{MPa} / \mathrm{s}$, (c) $8 \mathrm{MPa} / \mathrm{s}$ obtained by subtracting Fig. 11(a) from Figs. 11(b), (c), (d), respectively.

dependence of phase transformation and from anelastic deformation such as sliding along the crack-surface or along the shear band.

Lastly, since phase transformation involves a volume change, it is informative to evaluate the volumetric strain response under cyclic loading conditions. This is done by recording the radial strain and axial strain simultaneously. In Fig. 15, two sets of curves of axial plastic strain, radial plastic strain and volumetric plastic strain, are plotted against stress, where the volumetric strain is obtained by summing axial plastic strain and twice the radial plastic strain. For the axial strain there is a stress rate dependence which is similar to that described previously; this will not be discussed further here. For the radial strain, we note that it is always of the opposite sign of the axial strain, indicating a significant deviatoric contribution. Moreover, since microcracks induced during the tensile half-cycle are probably preferentially aligned perpendicular to the loading axis, their contribution to the radial strain is minimal. ${ }^{43}$ This partially accounts for the much smaller radial strain and its relative concave feature, unlike that of axial strain. Finally, the direct evidence of transformation plasticity comes from the volumetric strain, which increases in both tensile and compressive loading. Since an increase in volume in compression is not expected for microcracking and can come only from $t$ to $m$ transformation, such a transformation must have taken place both in tension and in compression. The stress asymmetry, signaled by a larger volumetric strain in tension than in compression, is also consistent with the operation of the above transformation.

\section{(4) Development of Steady-State Damage}

To monitor the development of the steady-state hysteresis loops (Figs. 7 and 9), the maximum plastic strain in tension and the plastic strain range of each cycle were recorded continuously. Some of these data in Mg-PSZ are plotted against fatigue cycles for various stress levels, as shown in Figs. 16 and 17. The accumulation of both accelerates considerably at higher stresses, judging from the data shown in Fig. 17. The shift of the maximum plastic strain toward the positive strain region is direct evidence of the accumulation of permanent fatigue damage (Fig. 16(a)). This strain accumulation is sometimes referred to as "cyclic creep" in the literature and should become especially prominent in the presence of tensioncompression asymmetry. (In stress-controlled cycling, the strain accumulation is positive/negative if the tensile yield stress is lower/higher than the compressive yield stress.) Conceivably, such strain accumulation could eventually lead to fatal failure. This should occur rapidly at stresses above $400 \mathrm{MPa}$ in $\mathrm{Mg}-\mathrm{PSZ}$, according to Fig. 17. Indeed, such a stress marks the fatigue tolerance for the material at a run-out cycle of $10^{3}$. Accompanying the increase in strain range is a tendency for cyclic strain softening; i.e., the hysteresis loop is progressively tilted toward the strain axis as cycling proceeds. An example of this development is shown in Fig. 18. We also found the loop width increased somewhat during cycling, but the increase was relatively small.

In the case of 3 Y-TZP, very little strain accumulation was found under fully reversed cyclic loading conditions, despite the quite prominent hysteresis loops at high peak stresses, as shown previously in Fig. 7. However, we did observe cyclic strain softening during cycling, judging from the decreasing tilt angle of the hysteresis loop, which would indicate fatigue damage due to microcrack accumulation. In our previous study of 3 Y-TZP, a mean-stress dependence of cumulative plastic strain was revealed. This is consistent with our present result of little strain accumulation in fully reversed cyclic loading, presumably because of the vanishing mean stress. Such a mean-stress dependence probably also exists in Mg-PSZ in view of its stronger capacity for dilatant transformation plasticity. This, however, was not investigated in the present study. 

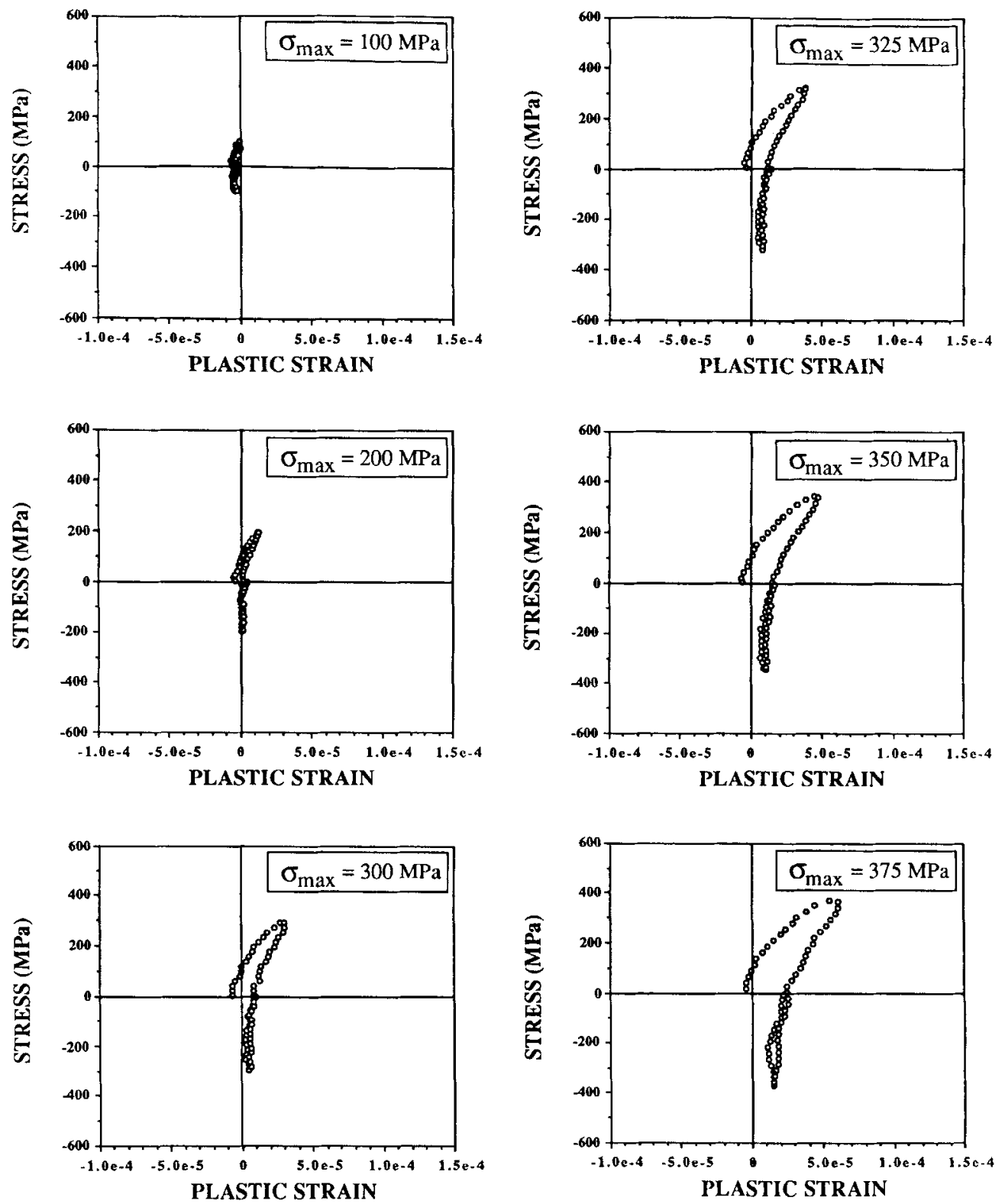

Fig. 13. Hysteresis loops of $\mathrm{Mg}-\mathrm{PSZ}$ at a stress rate of $200 \mathrm{MPa} / \mathrm{s}$.

\section{Discussion}

The two mechanisms involved in cyclic deformation of zirconia-containing ceramics are the same as those in monotonic deformation..$^{4(-43}$ The only difference lies in the magnitude of the strain (with studies on cyclic deformation generally limited to smaller strain ranges to avoid immediate failure) and in the reversible nature of cyclic deformation. In 3 YTZZP, microcracking is more significant than transformation plasticity, whereas in Mg-PSZ both can be important, depending on the stress range and the stress rate. Naturally, many observations on deformation characteristics noted in the previous studies of monotonic deformation are applicable in the present study. In the following, the mechanistic origins of these characteristics are first described in view of the present and previous work.

\section{(1) Reversible Transformation Plasticity}

An applied stress is necessary to provide the driving force for the transformation. In Mg-PSZ and 3 Y-TZP, the requisite driving force follows a broad distribution depending on the potency of the nucleation sites. Apparent strain hardening is evident because a higher flow stress is demanded for operating less potent nucleation sites or for the further growth of exist- ing transformation variants. This seems to be the case in both monotonic and cyclic deformation. Since the transformation is dilatant, the flow stress is higher in compression than in tension.

The very strong rate dependence of transformation plasticity has been noticed previously in monotonic loading in Mg-PSZ and in Ce-TZP under certain circumstances. ${ }^{40-42}$ Adopting the standard thermal activation analysis for deformation kinetics, an activation volume has been calculated and found to be of the order of several unit cell volumes. Such a rate dependence may be attributed to the thermally activated, double-kink process, which is believed operational for the movement of tetragonal/monoclinic interface. ${ }^{4(0-42}$ The results of the present study of cyclic deformation are consistent with the above picture.

Monotonic deformation of both Mg-PSZ and 3Y-TZP is distinctly asymmetric in tension and in compression. For Mg-PSZ, the "yield stress" in tension is typically between $2 / 3$ and $1 / 2$ of that in compression. Therefore, according to Fig. 10, the compressive "yield stress" would be placed around $-600 \mathrm{MPa}$ versus $350 \mathrm{MPa}$ in tension. The asymmetry is also apparent in Fig. 6 for 3 Y-TZP. After cycling, although the cyclic stress-strain curve of the latter (Fig. 8) remains asymmet- 

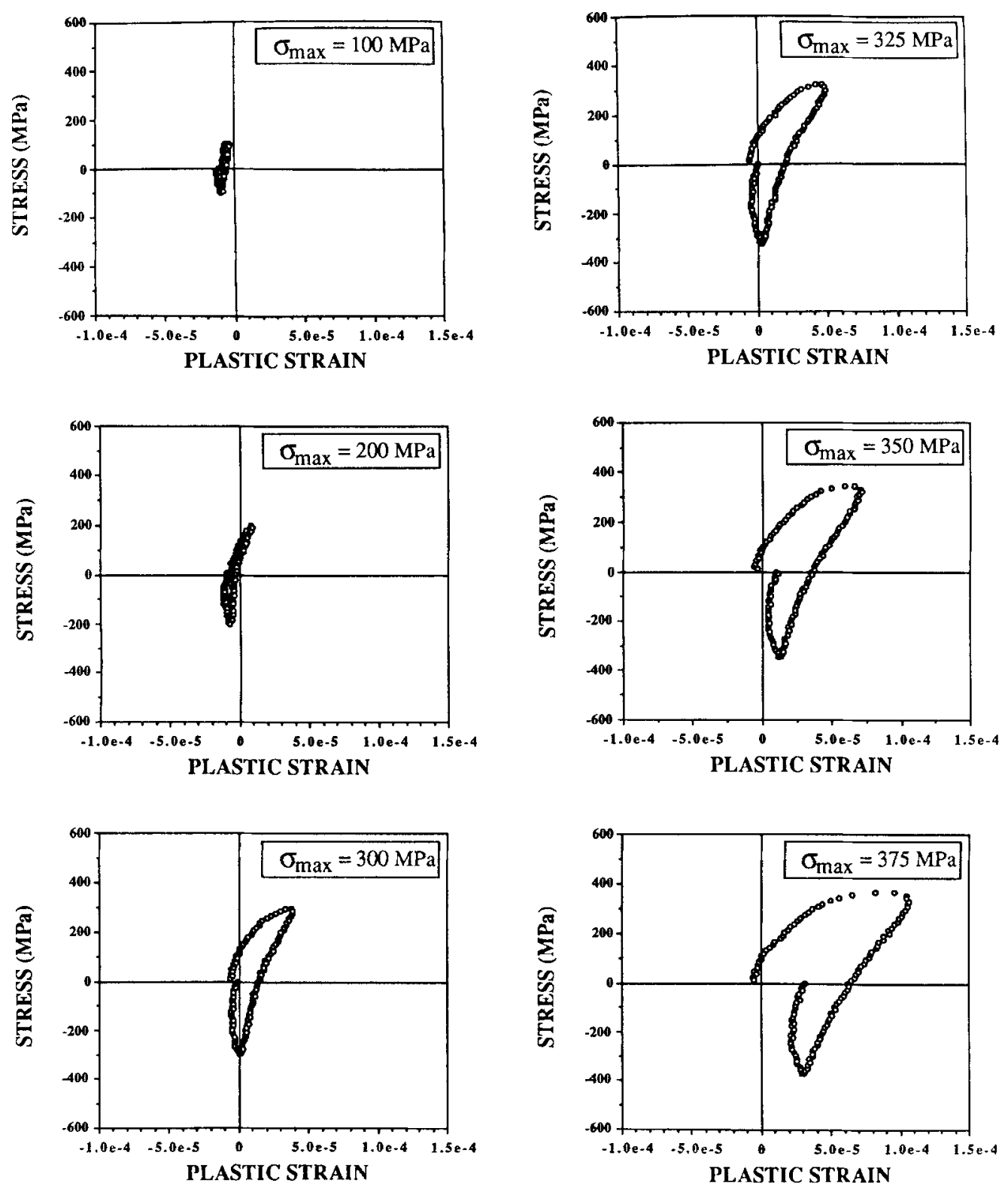

Fig. 14. Hysteresis loops of $\mathrm{Mg}$-PSZ at a stress rate of $20 \mathrm{MPa} / \mathrm{s}$.

ric, the one of Mg-PSZ (Fig. 10) has turned symmetric. This symmetrization development was found to occur only during stress-controlled cycling and to be achieved with the concurrent accumulation of "cyclic creep" strain in the tensile direction. If, instead, the plastic strain amplitude is used to control cycling, then the peak stress in tension is always smaller than that in compression. We can rationalize these results by envisioning the buildup of an internal stress. This internal stress is biased because of the larger magnitude of tensile strain compared to the compressive strain, e.g., in the first hysteresis loop in Fig. 2, and it opposes $t$ to $m$ transformation that results in a tensile strain in the forward direction. It also aids $m$ to $t$, or $t$ to $m$, or both, transformations in the reverse direction, as long as they generate compressive strains. This effect can be graphically appreciated by elevating the stress-plastic strain curve of Fig. 6 by an amount equal to the internal stress. At the steady state, the strain in tension approaches that in compression. This can be achieved under the stresscontrolled condition when the internal stress is just enough to symmetrize the resultant stress-plastic strain curve. Indeed, comparing Figs. 10 and 6, we expect that the cyclic stressplastic strain curve would correspond to the monotonic stress-plastic strain curve if we allow for an internal stress of $100 \mathrm{MPa}$. When the appropriate level of internal stress is estab- lished, the symmetrization of the cyclic stress-strain curve is complete and the cyclic creep is exhausted.

The reversible transformation in cyclic loading most likely operates by reversible movement of tetragonal/monoclinic interfaces. Such a scenario is plausible in view of the direct observations of pseudoelastic response and shape memory effect reported by several workers on zirconia ceramics. ${ }^{48-56}$ In this picture, the internal stress can be visualized as a bias, composed of dislocations and other stress sources, against the forward motion of the martensitic interfaces. The time required for the buildup of such internal stress sources, through repeated deformation cycles, determines the time required for attaining the steady-state hysteresis loop.

\section{(2) Microcracking}

A sufficiently high local tensile stress is required for the nucleation and the spontaneous propagation of an internal crack to its equilibrium size. ${ }^{51}$ Since the local tensile stress is the sum of the applied stress and the residual stress, the variation of the residual stresses at different parts of the material and the potency distribution of the nucleation sites necessarily cause some variation in the threshold stress for microcracking. Such an internal fracture process in a brittle material, occuring at ambient temperature, is usually athermal. Thus, 


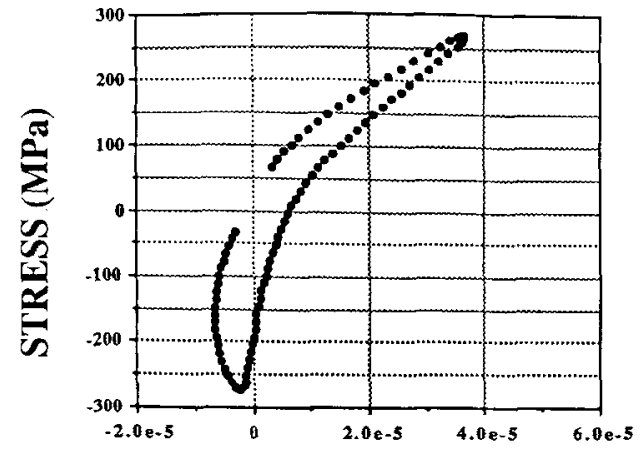

AXIAL PLASTIC STRAIN
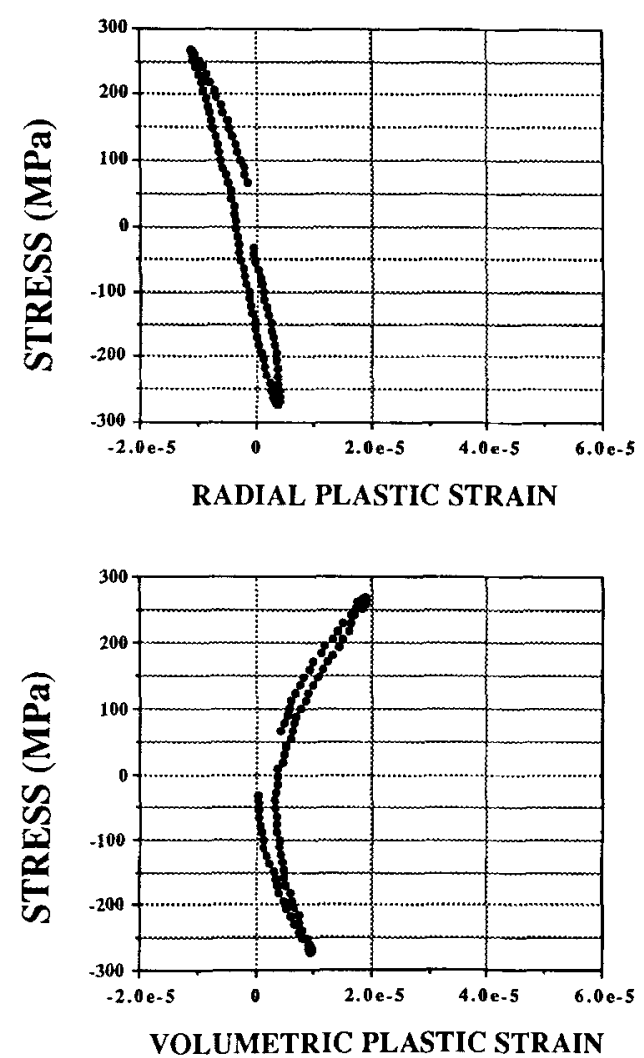

(a)

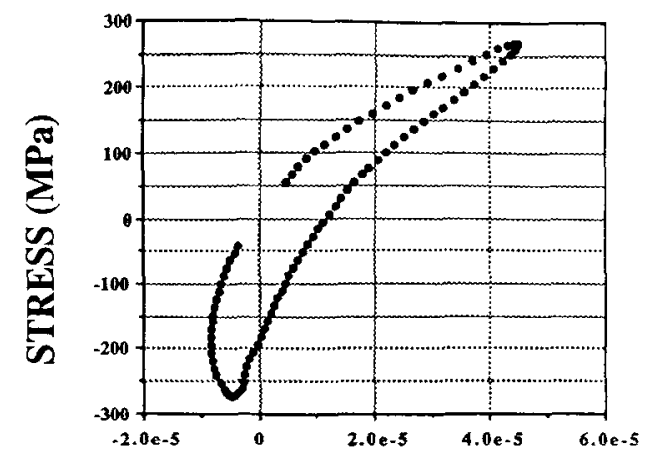

AXIAL PLASTIC STRAIN
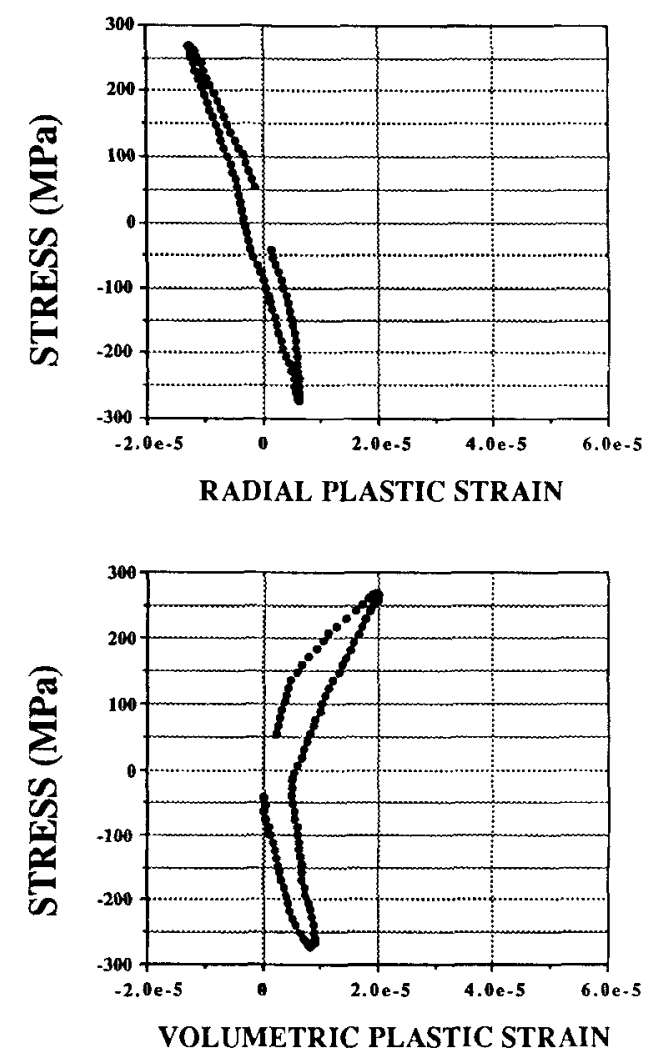

(b)

Fig. 15. Hysteresis loops of Mg-PSZ at (a) $60 \mathrm{MPa} / \mathrm{s}$ and (b) $6 \mathrm{MPa} / \mathrm{s}$, showing plastic axial strain, radial strain, and volumetric strain separately.

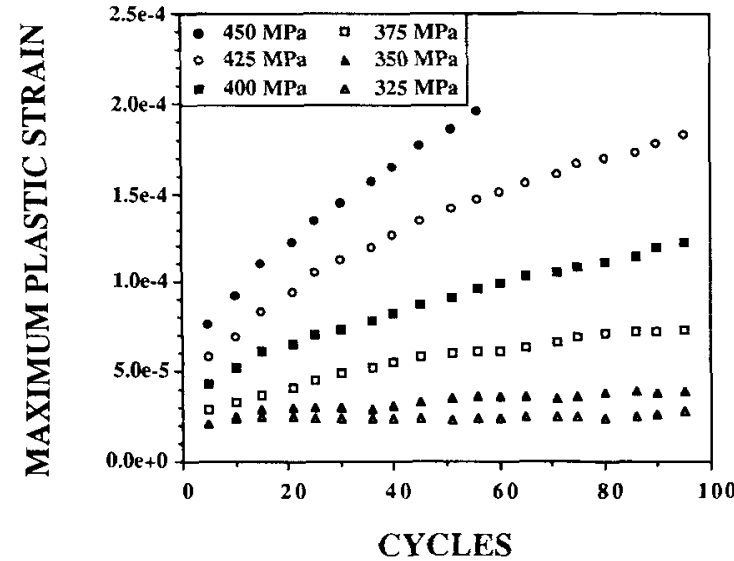

(a)

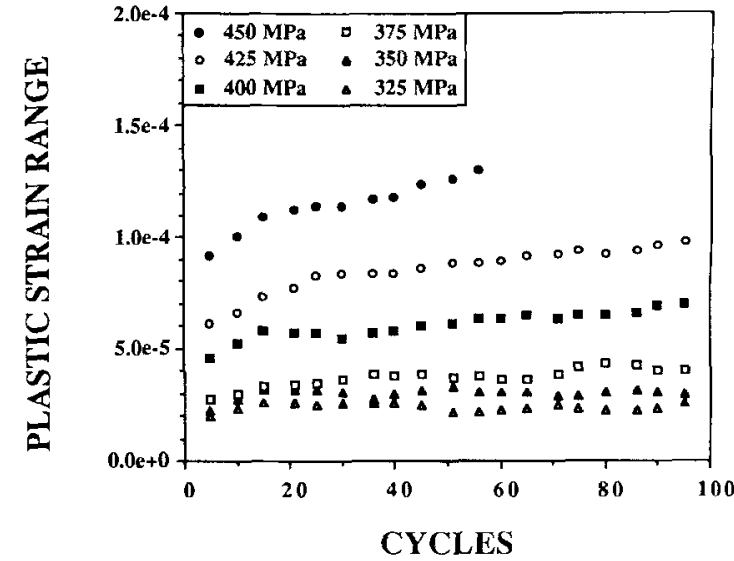

(b)

Fig. 16. (a) Maximum plastic strain versus fatigue cycles and (b) plastic strain range versus fatigue cycles. 


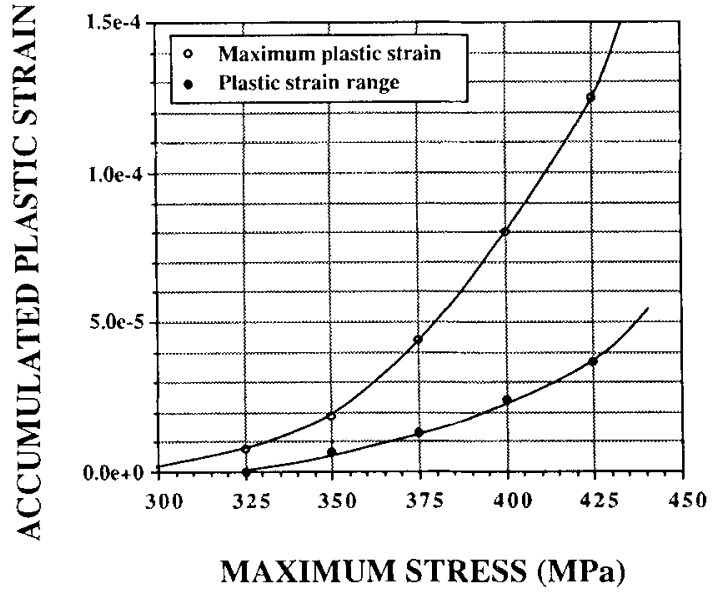

Fig. 17. Plastic strain accumulated after 100 cycles versus maximum stress.

microcracking is typically rate independent. Friction also exists in microcracking. It has long been recognized that, microscopically, crack facets are more likely at an inclination from the macroscopic crack plane than not. For this reaction, crack opening or closing requires not only a normal displacement but also a shear displacement. A friction acting against the shear displacement of the inclined facets may thus result. The main asymmetry of microcracking is due to crack closure in compression, which does not seem to be affected by stress cycling. The general features of both the monotonic and cyclic stress-plastic strain curves of 3Y-TZP are consistent with the above picture.

Direct micrographic evidence for microcracking may be sought using microscopy techniques. From the change in the elastic compliance after fatigue, the normalized density of microcracks (defined as $\mathrm{Na}^{3}$ where $a$ is the crack radius and $N$ is the number density per unit volume) has been estimated to be around $10^{-3}$ from our previous study of 3 Y-TZP. ${ }^{35}$ Considcring the very thin crack opening, the small size of the crack length, and the low density of such cracks, direct observation of fatigue microcracks in the scanning electron microscope or light microscope is probably unrealistic. Therefore, we prepared a thin specimen for examination in a transmission electron microscope. The specimen was cut parallel to the loading axis of the fatigue specimen (tested at $\sigma_{\max }=500 \mathrm{MPa}, R=$ 0.8 at $1 \mathrm{~Hz}$ and failed after 10523 cycles) to have the best chance to intersect microcracks which were expected to lie parallel to the loading axis. In this specimen, the total volume of the thin area transparent to electrons was estimated to be $10 \mu \mathrm{m}^{3}$, although the actual volume, carefully examined for

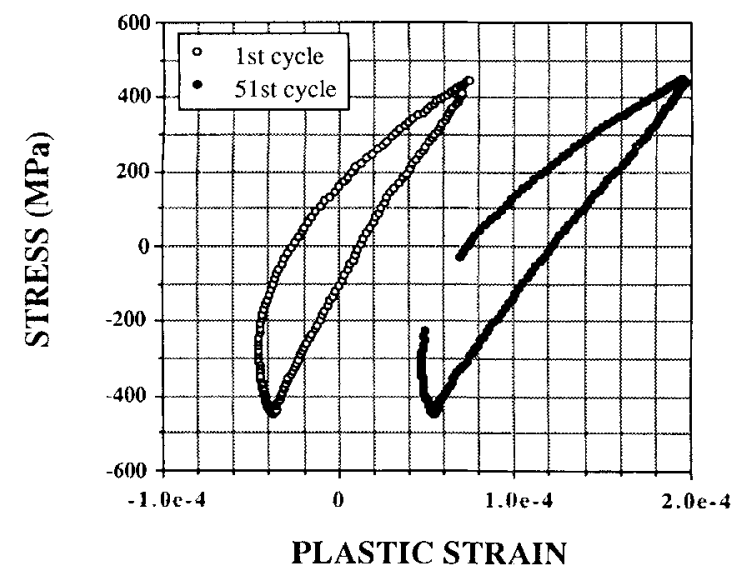

Fig. 18. 1st and 51st hysteresis loops of Mg-PSZ at $0.25 \mathrm{~Hz}$.

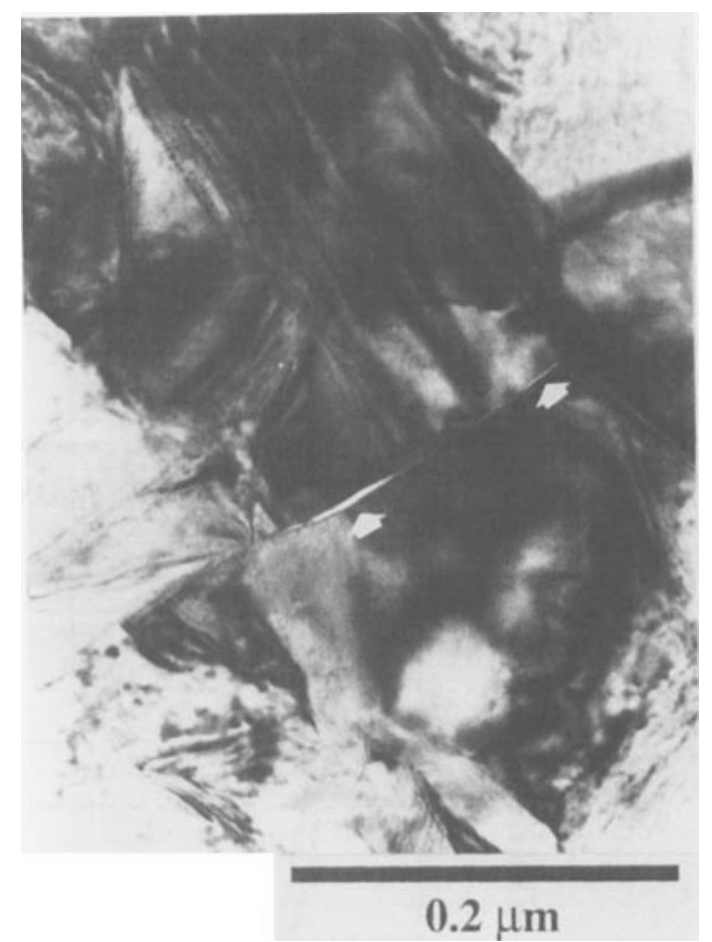

Fig. 19. TEM micrograph of 3Y-TZP after fatigue shows a lenticular microcrack along the grain boundary (as indicated by arrows).

evidence of microcracks, was much lower because of grain orientation and thickness variation. Although some porosity at four-grain junctions was occasionally observed throughout the specimen, we found only one microcrack along the grain boundary. This microcrack is shown in Fig. 19 and has a crack radius of $0.1 \mu \mathrm{m}$. Using the above estimated volume of $10 \mu \mathrm{m}^{3}$, it gives a normalized crack density of $10^{-4}$, which is not unreasonable. To our knowledge, this is the first TEM micrograph of fatigue microcracking of ceramics ever reported.

In Mg-PSZ, a rate-dependent, apparently anelastic, component seems to operate. As we explained in Section II, one interpretation of such deformation is the crack-face sliding, which might be further coupled to the sliding of the ligament linked to a microcrack, such as a shear band or a grain boundary. This more complicated case can arise when microcracking and transformation are operating simultaneously. In Mg-PSZ, the formation of transformation shear bands is common ${ }^{40,41}$ and has been shown to cause microcracking at their intersections with grain boundaries. ${ }^{43}$ Such a synergism could be responsible for the rate-dependent, apparently anelastic, strain in Mg-PSZ at lower stress rates.

\section{(3) Cyclic Softening and Fatigue Damage}

In the Introduction, we mentioned that in the fatigue literature cyclic hardening or softening can be ascertained by comparing the monotonic and cyclic stress-strain curves. ${ }^{1}$ Such a practice becomes questionable in the presence of stress asymmetry and the gradual development of an internal stress. In the present case, the tensile portion of the cyclic stress-plastic strain curve is "harder" than that of the monotonic stressplastic strain curve, and vice versa for the compressive portion, primarily because of the development of the internal stress that counters the stress asymmetry. Therefore, the comparison of cyclic and monotonic stress-strain curves is not very meaningful for the purpose of discerning cyclic hardening or softening. As we already reported in Section IV(4), a direct inspection of the evolution of the hysteresis loops established the softening nature of both Mg-PSZ and 3Y-TZP in cyclic deformation.

We have also demonstrated recently that in 3 Y-TZP, preexisting internal flaws can grow at a cyclic stress level of the order 
of $400 \mathrm{MPa}$ and that the lifetime of this material in uniaxial tension-compression fatigue is controlled by the growth of the most severe internal flaw. ${ }^{35.36}$ Similar findings have also been obtained for Mg-PSZ. According to these studies, the stresses corresponding to a "fatigue limit" for a run-out cycle of 10000 coincide approximately with the stresses when the plastic strain accumulation or cyclic softening becomes severe. Although such a measure of damage as strain accumulation or cyclic softening reflects only the average local damage over a large volume and is not directly connected to the crack tip processes, this coincidence nevertheless provides us some confidence in identifying the mechanisms of fatigue damage. Of course, the detection of a bulk fatigue damage should not be regarded as the necessary condition for fatigue failure. It is entirely conceivable that a sufficiently large flaw may be present, and it may undergo rapid crack growth at a fatigue stress level which otherwise results in no detectable bulk fatigue strain.

\section{Conclusions}

(1) Two distinct fatigue deformation mechanisms, microcracking and transformation plasticity, have been identified in 3 Y-TZP and Mg-PSZ.

(2) Microcracks form in the tensile half-cycle and partly close in the compressive half-cycle, although closure is usually not complete even at a substantial compressive stress. This is most evident in 3 YTZP, in which direct TEM evidence for microcracking has been presented for the first time. In Mg-PSZ, additional microcrack deformation of an anelastic nature has also been observed in the compressive half-cycle, after unloading from the peak compressive load. This may be attributed to crack-surface sliding or other similar sliding mechanisms.

(3) For 3Y-TZP, phase transformation prevails only at very low stress ranges, while microcracking dominates at higher stress ranges. For $\mathrm{Mg}$-PSZ, both phase transformation and microcracking are operational for all stress ranges, while the former becomes more pronounced at higher stress ranges.

(4) Transformation plasticity is initially much more favored in the tensile half-cycle than in the compressive half-cycle, although $t$ to $m$ transformation has also been detected in the compressive half-cycle, as evident from the volume increase in Mg-PSZ. Reverse transformation, from $m$ to $t$ phase, occurs during unloading from peak tensile and peak compressive stresses.

(5) As stress cycling proceeds under a stress control, an internal stress develops to oppose the forward transformation and to assist the reverse transformation. Concurrently, strain accumulation (cyclic creep) occurs in the tensile direction because of the lower tensile transformation stress compared to the compression one. As strain accumulation gradually becomes exhausted, the steady-state stress-plastic strain curve becomes symmetric with respect to the mean stress level of the stress cycle. This development is most evident in Mg-PSZ.

(6) Cyclic deformation in Mg-PSZ and 3Y-TZP is strongly dependent on the stress rate or frequency. At very high stress rates, transformation plasticity can be suppressed and only microcracking remains. Transformation plasticity is more prominent at lower stress rates. Microcracking is usually rate independent, although crack surface sliding or other similar sliding mechanisms may impart a rate dependence to this mechanism. The latter is most evident in Mg-PSZ, where a synergism between microcracking and transformation plasticity is probable.

(7) Cyclic softening has been observed regardless of which deformation mechanism is dominant. Such softening may be taken as direct evidence of fatigue damage.

\section{References}

R.W. Landgraf, J. Morrow, and T. Endo, "Determination of the Cyclic Stress-Strain Curve,"J Mater, 4 [1] 176-88 (1969).

${ }^{2}$ B. K. Sarkar and T. G.T. Glinn, "Fatigue Behavior of High- $\mathrm{A}_{2} \mathrm{O}_{3}$ Ceramics," Trans. Br. Ceram. Soc, 69, 199-203 (1970).
${ }^{3}$ D. A. Krohn and D. P. H. Hasselman, "Static and Cyclic Fatiguc Behavior of a Polycrystalline Alumina," J. Am. Ceram. Soc., 55 [4|208-11 (1972).

${ }^{4}$ C. P. Chen and W. J. Knapp, "Fatigue Fracture of an Alumina Curamic at Scveral Temperatures"; pp. 691-707 in Fracture Mechanics of Ceramics, Vol. 2. Edited by R. C. Bradt et al. Plenum Press, New York, (1973).

${ }^{5} \mathrm{R}$. Kossowsky, "Cyclic Fatigue of Hot-Pressed $\mathrm{Si}_{3} \mathrm{~N}_{4}, " \mathrm{~J}$. Am. Ceram. Soc., 56 [10] $531-35$ (1973)

"H.N. Ko, "Fatigue Strength of Sintered $\mathrm{Al}_{2} \mathrm{O}_{3}$ under Rotary Bending," J. Mater. Sci. Lett., 5, 464-66 (1986)

${ }^{7}$ L. Ewart and S. Suresh, "Dynamic Fatigue Crack Growth in Polycrystalline Alumina under Cyclic Compression," J. Mater. Sci. Lett., 5, 744-48 (1986).

${ }^{\mathrm{x}} \mathbf{L}$. Ewart and S. Suresh, "Crack Propagation in Ceramics under Cyclic Loads," J. Mater. Sci., 22, 1173-92(1987).

${ }^{4} \mathrm{H}$. N. Ko, "Cyclic Fatigue Bchavior of Sintered $\mathrm{Al}_{2} \mathrm{O}_{3}$ under Rotary Bending," J. Mater. Sci. Lett., 6. 801-805 (1987).

10T. Kawakubo and K, Komeva, "Static and Cyclic Fatigue Behavior of a Sintered Silicon Nitride at Room Temperature,"J. Am. Ceram. Soc., 70 [6] $400-405(1987)$

${ }^{11}$ I. Mackawa, H. Shibata, and A. Kobayashi, "Bending Fatigue of $\mathrm{Al}_{2} \mathrm{O}_{2}-$ $\mathrm{ZrO}$ Ccramics," I. Soc. Mater. Sci. Jon., 36 [409] 1116-27(1987).

${ }^{12} \mathrm{R}$. H. Dauskardt, W. Yu, and R. O. Rilchie, "Fatigue Crack Propagation in Transformation-Toughened Zirconia Ceramic," I. Am. Ceram. Soc. 70 [10] C-248-C-252 (1987)

${ }^{13}$ K. J. Bowman, P. E. Reyes-Morel, and I-W. Chen. "Reversible Transformation Plasticity in Uniaxial Tension-Compression Cycling of Mg-PSZ," Mater. Res. Soc. Symp. Proc., 78, 51-58 (1987)

${ }^{1+}$ M.V. Swain and V. Zelizko, "Compression of Static and Cyclic Fatigue on Mg-PSZ Alloys"; pp. 545-606 in Advances in Ceramics, Vol, 243. Science and Technology of Zirconia III. Edited by S. Somiya, N. Yamamoto, and II. Hanagida. American Ceramic Society. Westerville, OH 1, 1988.

${ }^{15} \mathrm{~V}$. Zelizko and M.V. Swain. "Influence of Surface Preparation on the Rotaling Flexural Fatigue of Mg-PS7." J. Mat'f. Sci., 23, 1077-82 (1988)

${ }^{1}$ M. Takatsu, H. Kamiya, K. Ohya, K. Ogura, and T. Kinoshita, "Effect of Vibrated Cyclic Fatigue Properties of Ceramics from Stress Load Condition," J. Ceram. Soc. Jpn., 96 [10|99(0-96 (1988).

${ }^{17} \mathrm{~S}$. Suresh and J. R. Brockenbrough, "Theory and Experiments of Fracture in Cyclic Compression: Single Phase Ceramics. Transforming Ceramics and Ceramic Composites," Acta Mctall., 36 [6] 1455-70 (1988).

${ }^{1 \mathrm{M}}$ M. Masuda, T. Soma. M. Matsui, and I. Oda, "Fatigue of Ceramics (Part 1)-Fatigue Behavior of Sintered $\mathrm{Si}_{3} \mathrm{~N}_{4}$ under Tension-Compression Cyclic Stress,"J. Ceram. Soc. Jpn., 96 [3] 277-83 (1988).

${ }^{19} \mathrm{~S}$. Horibe, "Cyclic Fatigue Crack Growth from Indentation flaw in $\mathrm{Si}_{3} \mathrm{~N}_{4}$, , J. Mater. Sci. Lett. 7 [7] 725-27 (1988).

2"L. A Sylva and S. Suresh, "Crack Growth in Transforming Ceramics under Cyclic Tensile Loads," J. Mater. Sci., 24, 1729-38 (1989).

${ }^{2 M}$ M. Masuda, N. Yamada, T. Soma, M. Matsui, and I. Oda, "Fattigue of Ceramies (Part 2) Cyclic latigue Properties of Sintered $\mathrm{Si}_{3} \mathrm{~N}_{4}$ at Roxm Tem. perature,"J. Ceram. Soc. Jpn., 97 [5] 520-24 (1989)

${ }_{22}^{2}$ M. J. Reece, F. Guiu, and M. I. R. Sammur, "Cyclic Iatigue Crack Propagation in Alumina under Direct Tension-Compression Loading, J. Am. Ceam, Soc, 72 [2] $348-52$ (1989).

${ }_{2}^{2}$ D. G. Jensen, V. Zclizko, and M.V. Swain, "Small Flaw Static Fatigue Crack Growth in Mg-PSZ," J. Mater. Sci. Lett., 8, 1154-57 (1989).

${ }^{24}$ M. Masuda, T. Soma. M. Matsui and I. Oda "Fatigue of Ceramics (Part 3) Cyclic Fatigue Bchavior of Sintered $\mathrm{Si}_{3} \mathrm{~N}_{4}$ at fligh Temperature." J. Ceram. Soc. Jpn., 97 [6] 612-18 (1989).

${ }_{25}$ H. Kamiya, M. Takatsu, K. Ohya, M. Ando, and A. Hattori, "Iffect of Microstructure on Cyclic Fatigue Properties of $\mathrm{Al}_{2} \mathrm{O}_{3}$ Ceramics and $\mathrm{Al}_{2} \mathrm{O}$ Composites," J. Ceram. Soc. Jpn., 98 [5] 456-6.3 (1990)

${ }^{2} \mathrm{M}$. Takatsu, K. Ohya, and M. Ando, "The Relationship between Cyctic Fatigue Properties and Microstructures of Sintered Silicon Nitride Ceramics." J. Ceram. Soc. Jpn. 98 [5] 490-98 (1990).

${ }^{27}$ A. A. Steffen, R. H. Dauskardt, and R. O. Ritchie, "Cyclic FatigucCrack Propagation in Ceramics: Long and Small Crack Behavior"; pp. 74552 in Fatigue 90. Proceedings of the Fourth International conference on Fatigue and Fatigue Thresholds. Edited by II. Kitagawa and T. Tanaka. Materials and Component Engineering Publications Ltd., Birmingham, UK, 1996).

${ }^{28}$ D. C. Cardona and C. J. Becvers, "Fatigue Behavior of Zirconia-Ceria Alloys"; see Ref. 27, pp. 1023-29.

${ }^{2 y}$ R. H. Dauskardt, D. B. Marshall, and R.O. Ritchic, "Cyclic FatigucCrack Propagation in Magnesia-Partially-Stabilized Zirconia Ceramics, J. Am. Ceram. Soc., 73 [4] 893-903 (1990).

${ }^{3 n} \mathrm{H}$. Kishimoto, A. Ueno, and H. Katwamoto, "Crack Propagation Behavior of $\mathrm{Si}_{3} \mathrm{~N}_{4}$ under Cyclic Loads - Influence of Difterence in Matcrials": see Ref. 27, pp. $727-32$.

${ }^{1}$ A. Ueno, H. Kishimoto, H. Kawamoto and M. Asakura, "Crack Propagation Behavior of Sintered Silicon Nitride under Cyclic Load of High Stress Ratio and High Frequency": see Ref, 27, pp, 73,3-38.

32J. F. Tsai, C. S. Yu, and D. K. Shetty, "Fatigue Crack Propagation in Ceria-Partially-Stabilized Zirconia $\left(\mathrm{CeO}_{2}-\mathrm{TZP}\right)$ Ceramic," J. Am. Ceram. Soc., 73 [10] 2992-3001 (1990)

${ }^{33} \mathrm{~S}$. Horibe, "A New Method for Tension-Compression Fatigue Tasting of Ceramic Materials," J. Mater. Sci. Lett, 9, 745-47 (1990).

${ }^{34}$ R. H. Dauskardt, W. C. Carter, D. K. Veirs, and R. O. Ritchie, "Transient Subcritical Crack-Growth Behavior in Transformation-Toughened Ceramics." Acta Metall., in press.

${ }^{35}$ S.-Y. Liu and I-W. Chen, "Fatigue of Yttria-Stabilized Zirconia: I, Fatigue Damage, Fracture Origins, and Lifeti..: Prediction,"J. Am. Ceram. Soc., 74 
[6] 1197-205 (1991).

"S.-Y. Liu and I-W. Chen, "Fatigue of Yttria-Stabilized Zirconia: II, Crack Propagation, Fatigue Striation, and Short-Crack Behavior," J. Am. Ceram. Soc., $74[6] 1206-216(1991)$

${ }^{37} \mathrm{I}-\mathrm{W}$. Chen and S.-Y. Liu, "Constitutive Relations for Mechanical Fatigue in Zirconia Ceramics"; pp. 153-68 in Fatigue of Advanced Materials. Edited by R. O. Ritchie, B.V. Cox, and R. H. Dauskardt. Materials and Components Engineering Publications Ltd., Birmingham, U.K., 1991.

${ }^{\$}$ J. Burbach, "On the Physical Justification of the Term 'State of Fatigue of Materials under Cyclic Loading" "; pp. 185-212 in Cyclic Stress-Strain Behavior-Analysis, Experimentation and Failure Prediction. ASTM STP 519 American Society for Testing and Materials, Philadelphia, PA, 1973

${ }^{39}$ W. Elber, "The Significance of Fatigue Crack Closure"; pp. 230-42 in Damage Tolerance in Aircrafi Structures. ASTM STP 486. American Society for Testing and Materials, Philadelphia, PA, 1971

40I.W. Chen and P. E. Reyes-Morel, "Transformation Plasticity and Transformaton Toughening in Mg-PSZ and Ce-TZP," Mater. Res. Soc. Symp. Proc., 78, 75-88 (1987).

"I-W. Chen and P. E. Reyes-Morel, "Implications of Transformation Plasticity in $\mathrm{ZrO}$-Containing Ccramics: I, Shear and Dilatation Effects," J. Am Ceram. Soc, 69 [3] 181-89 (1986).

${ }^{42}$ P. E. Reyes-Morel and I-W. Chen, "Transformation Plasticity of $\mathrm{CeO}_{2}$ Stabilized Tetragonal Zirconia Polycrystals: I, Stress Assistance and Auto- catalysis," J. Am. Ceram. Soc., 71 [5] 343-53 (1988).

${ }^{43}$ P. E. Reyes-Morel and I-W. Chen, "Stress Biased Anisotropic Microcracking in Zirconia Polycrystals," J. Am. Ceram. Soc, 73 [4] 1026-33 (1990).

${ }^{44}$ R. C. Garvie, R. H. Hannink, and R. T. Pascoe, "Ceramic Steel?" Nature (London), 258 [5537] 703-704 (1975).

${ }^{45}$ A. G. Evans and R.M. Cannon, "Toughening of Brittle Solids by Martensitic Transformations," Acta Metall., 34, 761-800 (1986).

${ }^{4} \mathrm{~J}$. Lank ford, R. A. Page, and L. Rabenberg, "Deformation Mechanisms in Yttria-Stabilized Zirconia," J. Mater. Sci., 23, 4144-56 (1988).

${ }^{47}$ ASTM Standard E.606-80, "Standard Recommended Practice for Constant-Amplitude Low Cycle Fatigue Testing"; pp. 652-69 in ASTM Annual Book of Standards, Vol 3.01. American Society for Testing and Materials, Philadelphia, PA, 1983.

${ }^{48} \mathrm{P}$. E. Reyes-Morel, J. S. Cherng, and I-W. Chen, "Transformation Plasticity in Ce-TZP: II. Pseudoelasticity and Shape Memory Effect," $J, A m$. Ceram. Soc., 71 [8] 648-57 (1988)

${ }^{49} \mathrm{D}$. B. Marshall and M. R. James, "Reversible Stress-Induced Martensit ic Transformation in $\mathrm{ZrO}_{2}, " J$. Am. Ceram. Soc., 69 [3] 215-17 (1986).

5il R. H. Hannink, J. R. Porter, and D. B. Marshall, "Direct Observation of Cyclic Phase Transformations in $\mathrm{ZrO}_{2}, " J$. Am. Ceram. Soc., 69 [6] C.116C-119 (1986)

${ }^{5}$ R.W. Davidge, "Cracking at Grain Boundaries in Polycrystalline Brittlo Materials," Acta Metall., 29, $1695-702$ (1981). 